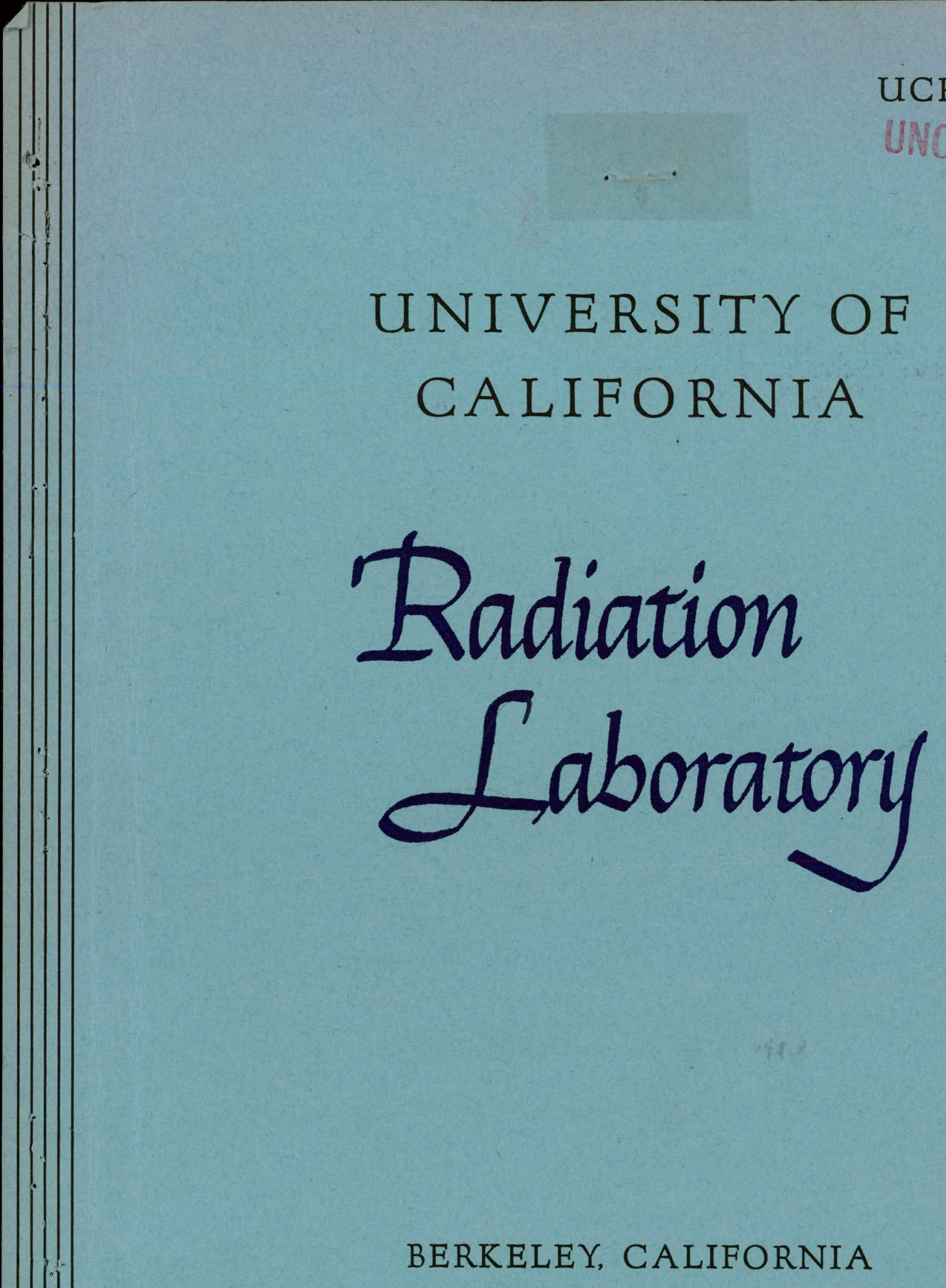




\section{DISCLAIMER}

This report was prepared as an account of work sponsored by an agency of the United States Government. Neither the United States Government nor any agency Thereof, nor any of their employees, makes any warranty, express or implied, or assumes any legal liability or responsibility for the accuracy, completeness, or usefulness of any information, apparatus, product, or process disclosed, or represents that its use would not infringe privately owned rights. Reference herein to any specific commercial product, process, or service by trade name, trademark, manufacturer, or otherwise does not necessarily constitute or imply its endorsement, recommendation, or favoring by the United States Government or any agency thereof. The views and opinions of authors expressed herein do not necessarily state or reflect those of the United States Government or any agency thereof. 


\section{DISCLAIMER}

Portions of this document may be illegible in electronic image products. Images are produced from the best available original document. 


$$
\begin{aligned}
& \therefore \\
& \text { UCRL }-2345
\end{aligned}
$$

UNIVERSITY OF CALIFORNIA

Radiation Laboratory

Contract No, W- 7405 -eng -48

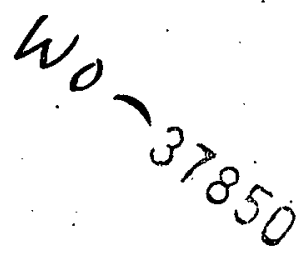

MEDICAL AND HEALTH PHYSICS QUARTERLY REPORT

April, May, June, 1953

September 21, 1953 


\title{
MEDICAL AND HEALTH PHYSICS QUARTERLY REPORT
}

\author{
April, May, June, 1953
}

\section{Table of Contents}

BIOLOGICAL STUDIES OF RADIATION EFFECTS

The Relation of Radioresistance to Budding in Saccharomyces

The Liquid Scintillation Counting of Tritium - and $\mathrm{C}^{14}$

Labeled Compounds.

THE METABOLIC PROPERTIES OF VARIOUS MATERIALS

TRACER STUDIES

Astatine in Rats and Monkeys

Radiographic Studies of Skeletons of Astatine-Treated Monkeys

RADIATION CHEMISTRY.

Acetic Acid Studies

Determination of Aldehydes and Ketones in Irradiated. Solutions of Organic Acids

Glycine Studies

HEALTH CHEMISTRY

Progress Report

HEALTH PHYSICS

Statistical Summary of Monitoring Program 
MEDICAL AND HEALTH PHYSICS QUARTERLY REPORT

April, May, June, 1953

\section{BIOLOGICAL STUDIES OF RADIATION EFFECTS}

John H. Lawrence, M. D., in charge

\section{THE RELATION OF RADIORESISTANCE TO BUDDING IN SACCHAROMYCES CEREVISIAE}

C. A. Beam, R. K. Mortimer, R. G. Wolfe, and C. A. Tobias

The $\mathrm{x}$-ray survival curves of many microorganisms have been shown to consist of decreasing exponential functions of the dose. This fact has generally been thought to signify the lethal effectiveness of single radiation events upon members of a population uniform in radiosensitivity ${ }^{l}$. In the (case of the) $x-r a y$ survival of haploid Saccharomyces cerevisiae, however, several independent investigators $2,3,4$ have found at high doses a departure from a simple exponential (see Fig. 4 A) which is most simply interpreted as representing the survival of a small fraction of highly radioresistant members of the treated population.

Some workers ${ }^{3}$ found diploid cells among the survivors of high $\mathrm{x}-$ ray doses and attributed the population heterogeneity in part to spontaneous diploidization in the haploid cultures. 'Others, 2,4 using strains of yeast that were "clumpy," thought the occasional clumps of a few cells to be the sole radioresistant component of their suspensions. Either diploid cells or clumps of haploids, if present, would constitute a more radioresistant component; the diploid by its known higher radioresistance, $2,3,4$ the clump by its obvious ability to form a colony unless all of the cells comprising it are destroyed by the radiation. The basis for a third explanation is provided by the early report ${ }^{5}$ that in yeast the onset of budding is accompanied by an increase in radioresistance.

The purpose of the present investigation was to reexamine the $\mathrm{x}$-ray survival of haploid yeast and to discover the cause of the anomalous radioresistance at high doses. Evidence will be presented which confirms the high radioresistance of budding yeast cells and establishes these cells as the radioresistant component of the populations studied.

Materials and Methods

The yeast used in the se experiments, a haploid strain of Saccharomyces cerevisiae, has been described in detail by Zirkle and Tobias. 3 Unless otherwise specified, the cells used were harvested from young cultures (10-18 hours, $30^{\circ} \mathrm{C}$; grown on yeast-extract dextrose agar- -0.5 percent yeast extract, 1 percent dextrose, 2 percent agar). The cells were suspended in water and in all cases thoroughly shaken to break up clumps of cells. 
In some experiments "starved" cells were employed. The se cells had been maintained under conditions of nitrogen starvation in buffer ( 2 percent dextrose, $\mathrm{M} / 20 \mathrm{KH}_{2} \mathrm{PO}_{4}$ ) for periods of from three to fourteen days. Several methods have been employed in these starvations, the simplest of which con-

- sisted in maintaining a suspension on a laboratory shaker and replenishing the medium after centrifugation at 2 - to 3 -day intervals.

The cells were irradiated with a low voltage beryllium-window $\mathrm{x}$ ray tube (Machlett OEG-60) operated at 50 $\mathrm{KV}$ and $25 \mathrm{ma}$. Under these conditions and with the biological specimen at a distance of $16 \mathrm{~cm}$ from the tube target, the dose rate was $252 \mathrm{r} / \mathrm{sec}$. The dose was measured with an ionization chamber having a thin beryllium window. This apparatus and its calibration are described in detail by Mortimer. 6

Two techniques of irradiation have been employed. In one, serial $1: 10$ dilutions were prepared of the initial cell suspension and $0.1-\mathrm{ml}$ aliquots 0 each spread upon the surface of yeast-extract dextrose agar in $10-\mathrm{cm}$ petri dishes: The dishes themselves without cover were then placed in the path of the $x$-ray beam and the previously adjusted machine turned on for the desired exposure time. Several plates were usually prepared for each dose and a choice of exposure times and dilutions provided the basis for a number of dose points. After exposure the petri dishes were incubated at $30^{\circ} \mathrm{C}$ for 48 hours at which time visible colonies were counted. Survival ratios were obtained by reference to unirradiated control plates.

The second technique, in which the survival ratio is determined by counting under the microscope young colonies developing from irradiated cells, has been described elsewhere. ${ }^{3}$ In the experiments reported here the colony size selected as minimal for survival ( 40 cells after 24 hours incubation at $30^{\circ}$ ) is one known to provide survival ratios which correspond closely to those obtained from the counting of macroscopic colonies. 10

Experimental

To better characterize the radioresistant component of populations of haploid yeast, survival curves were first extended to much higher doses than has been previously employed. Curves of this kind, typified by Fig. 1, show that whereas about 90 percent of the cells are killed according to a simple exponential with an LD 50 of $3100 \mathrm{r}$, the remaining radioresistant members (LD $50 \stackrel{\sim}{9}, 000, \mathrm{r}$ ) exhibit at high doses a complex multiple-hit relationship.

A - The Role of Clumps

For clumps to account for the radioresistant component of the survival curve would require (1) that the average number of cells in the clumps approximate the multiplicity observed in the survival of the radioresistant members of the population, and (2) that the frequency of observable clumps in the material used approximate the point of inception on the survival curve of the radioresistant component.

Assuming the cells of a clump to be independent units and their death to occur by independent radiation events, one can express the expected survival of a population of clumps of $\mathrm{K}$ cells each in the following fashion. 


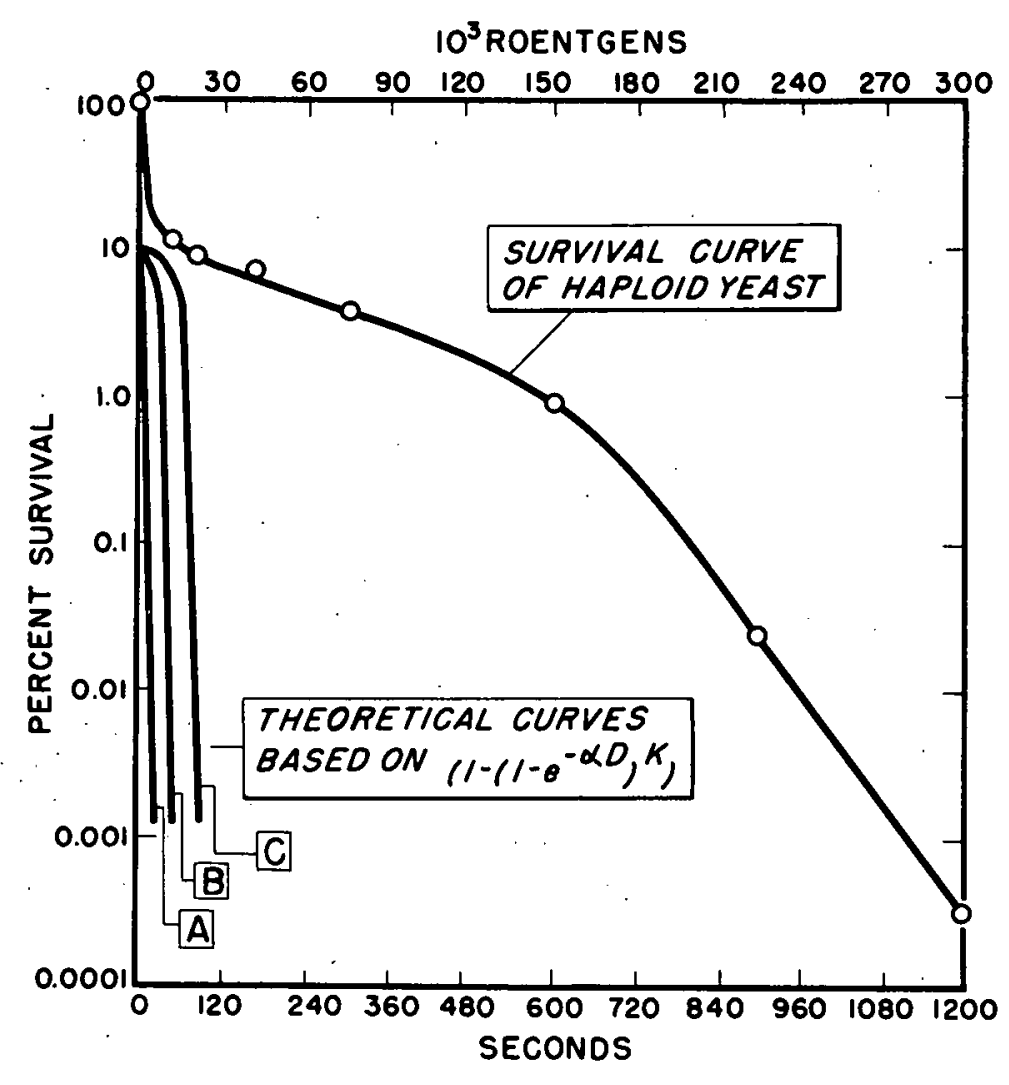

MU-5795

Fig. The x-riy survival of hiploid yest o observed survival curve

$A B$ and $C$ theoratical survival for curves for populations of clumps of $K$ cells; $A, K=1 ; B, K=100, C, K=1000$. 
The number $\mathrm{N}$ of survivors of a population consisting of No single haploid cells each requiring one hit for inactivation is represented by

$$
N=N_{0} e^{-a D}
$$

where $D$ is the dose of radiation and the constant a represents radiosensitivity. If $\mathrm{K}$ cells are clumped together, the number of survivors $M$ of a population of $\mathrm{M}_{\mathrm{O}}$ clumps of $\mathrm{K}$ cells each becomes*

$$
M=M_{0}\left[1-\left(1-e^{-a D}\right) K\right]
$$

Theoretical curves for various values of $K$ prepared from this equation and based upon the $\mathrm{LD}_{50}$ of the initial haploid exponential are shown in $F$ ig. 1 . It can be seen that a population of clumps of even $1, .000$ cells is too sensitive to account for the radioresistant component of the survival curve.

That ten percent of the colony-forming units of the cell suspensions used consist of clumps of this size is.inconsistent with the repeated observation that the frequency of small clumps ( 2 to 4 cells) is less than 0.1 percent and that of large clumps (over 10 cells) less than $10^{-4}$.

B - Heterogeneity for Radioresistance

That the presence of diploid cells could contribute appreciably to the observed radioresistant element of the population can be eliminated on grounds similar to those applicable to clumps. The well established $2,3,4$ radioresistance of diploid yeast $\left(L D_{50}=22,000 . r\right)$ is insufficient to account for a population moiety with an LD 50 of $90,000 \mathrm{r}$.

The possibility remained, however, that populations of haploid cells normally consist of two stable components in equilibrium, one the recognizable haploid showing exponential survival, the other possessing the unique properties evident in the radioresistant component of the survival curve.

Were this true, high doses of radiation should screen the surviving population of all but the radioresistant cells. The progeny of cells surviving large dose $s$ of radiation should then be more radioresistant than members of an unirradiated population. The necessary assumption that $\mathrm{x}$-rays do not produce radioresistant cells is supported by the knowledge (Tobias and Stepka 7 ) that the progeny of survivors from the exponential portion of the curve are unchanged in radiosensitivity.

Accordingly, thirty colonies arising from cells which had survived exposures of from 5,000 to 60,000 roentgens were isolated and subcultured. Preparations from these and from a control group of unirradiated isolates were then subjected to a single test dose of 15,000 roentgens. The results (Fig. 2) show that the survivors of high doses do not differ significantly in radiosensitivity from haploid cells which had not been previously irradiated. Moreover, survival curves at several dose points taken upon cultures from two other survivors of 60,000 roentgens were indistinguishable from the normal survival curve.

* Lea ${ }^{1}$, p. 319. 
C - Distribution of Radiosensitivities

It could be argued that the noninherited nature of the radioresistance supported the idea that the complexity of the survival curve reflected simply a distribution of radiosensitivities normal to a population of haploid cells. In this case any population would consist of subpopulations each of which would survive according to an exponential relationship appropriate to its radiosensitivity. The observed survival curve would represent the sum. One would expect, however, that in this summation the subpopulations would be inactivated in order of increasing radioresistance. The survival of a radioresistant population could not be interspersed between those of two more radiosensitive ones.

That a distribution of sensitivities would not yield a curve with an inflection can be given more exact expression*. If the probability of a cell having a sensitivity a is $\phi(a)$, the survival of a population of cells of $a^{\prime} s$ varying from 0 to $\infty$ is given by

$$
N=N_{0} \int_{0}^{\infty} \phi(a) e^{-a D} d a
$$

The second derivative of $\mathrm{N}$ with respect to $\mathrm{D}$ is always positive.

$$
\frac{d^{2} N}{d D^{2}}=N_{0} \int_{0}^{\infty} a^{2} \phi(a) e^{-a D \geq} 0
$$

Hence the survival curve of the population could show no inflection.

D - Budding and Radioresistance

The earliest correlation of budding cells with the radioresistant element of the yeast population lay in the observation that cells from older cultures where budding is infrequent showed lower origins of the resistant component of the survival curves (at about 1 percent survival) than did those from young cultures (about 10 percent):

A more precise correlation of budding with radioresistance was provided by the following experiment. Several small sterile coverslips were covered with a thin layer of yeast-extract dextrose agar and a fine grid was marked on the surface of each with the aid of a micromanipulator. An aqueous suspension of a four-day culture of haploid yeast was then spread on these surfaces and the location of each cell was mapped with reference to the grid and scored at the same time as to whether single or budding. These preparations were then given various doses of $x$-rays and placed on van Tiegham cells. After 24 hours' incubation at $30^{\circ} \mathrm{C}$, the preparations were examined microscopically and each prevariously mapped cell scored as to whether surviving (producing a colony of more than 40 cells) or killed. Figure 3 presents survival curves obtained in this fashion. The budding cells can be seen to be much more radioresistant than the "resting" ones. If the survival of budding cells were plotted from the 10 percent survival level the composite would closely resemble a typical survival curve.

The relationship between budding and radioresistance was further clarified by the use of the "starved" cells described above. It was hoped that

* We are indebted for this derivation to $R$. Wijsman. 


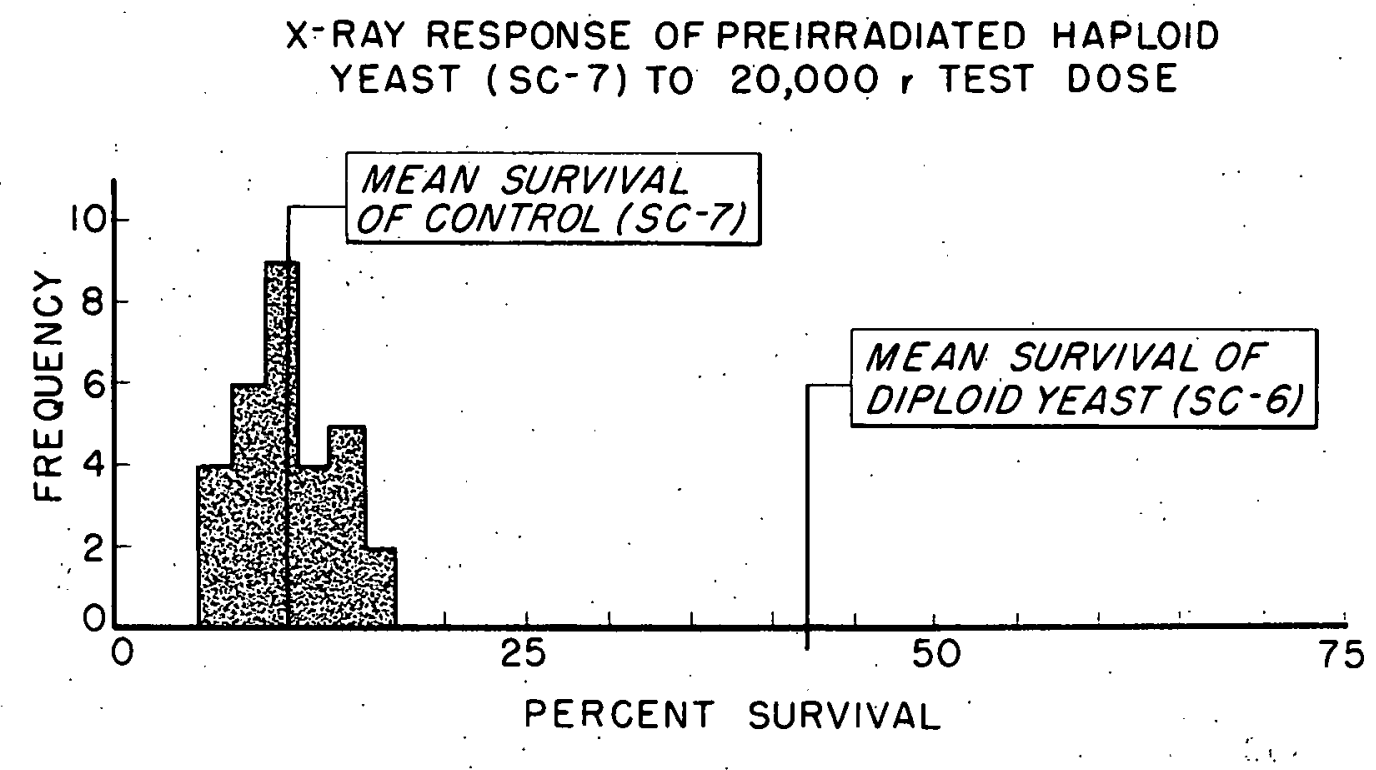

$X$-RAY RESPONSE OF PREIRRADIATED HAPLOID

YEAST (SC-7) TO 20,000 r TEST DOSE

MU 5624

Fig. ? 
under the conditions of nitrogen starvation (the presence of ample sugar, constant aeration, fresh medium to check the accumulation of waste products, and the absence of utilizable nitrogen), the cells wouldmultiply until their food reserves were depleted and that the percentage of dividing cells would be reduced. Growth in such preparatibns ceased within a few hours, and survival curves taken at intervals during the period of starvation (Fig. 4) show a progressive reduction of the proportion of radioresistant members of the population. In some instances the percentage of this component fell ultimately as low as 0.001 percent in curves similar to the single exponential relationships through six logarithmic cycles obtained with resting haploid yeast by Wood. 10 The percentage of budding cells, however, in these starved populations was never observed to fall much below 1.0 percent.

On the other hand, when the starved cells were given fresh nutrients, the onset of fresh budding was accompanied by a corresponding rise in the level of the radioresistant component of the survival curves. This relationship was observed in experiments in which survival curves and microscopic bud counts were obtained after various periods of incubation of the starved cells on yeastextract dextrose agar. The resistant components of these curves (Fig. 5) when extrapolated to zero dose provide estimations of the percentage of radioresistant members of the population at time of treatment. The percentage values of these extrapolations show a close positive correlation with the observed percentage of budding cells (Table I).

The rise above log phase level of both the radioresistant population and the percentage of buds, found in this experiment. (Table I), is not surprising since these cells, rendered more uniform by the starvation, enter the first division in approximate synchrony, whereas cells from a growing culture represent all stages of the division cycle.

The fact that radioresistance is associated with the appearance of new buds in a growing population but not with old ones remaining under conditions of starvation is amenable to cytological interpretation. In growing yeast, according to Delamater, 11 the formation of buds begins in anticipation of nuclear division. Furthermore, mature buds of cells from old cultures frequently lack nuclei and are replaced by new buds when the cell is transferred to fresh culture medium. These observations suggest that the radioresistance associated with budding is referable to nuclear division and probably to a very early stage of this process, since many of the buds represented in Table I were very small.

Preliminary observations on diploid and tetraploid yeast are consistent with a similar high radioresistance of the budding cells of these strains. These results will be presented elsewhere.

Discussion

The evidence presented above confirms the reported ${ }^{5}$ high radioresistance of dividing yeart cells and establishes these cells as the source of the resistant component of $x-r a y$ survival curves of haploid yeast. The present data rule out the possibility that the radioresistant component of the curves is due to clumps of cells or occasional diploid cèlls. They also provide an explanation for the report by Latarjet ${ }^{8}$ that clumps of cells possess a radioresistance highly in excess of that which would be expected on the basis of the number of individual cells composing the clumps, since a clump of four or five yeast cells from a growing culture could be expected to contain at least one budding cell. 


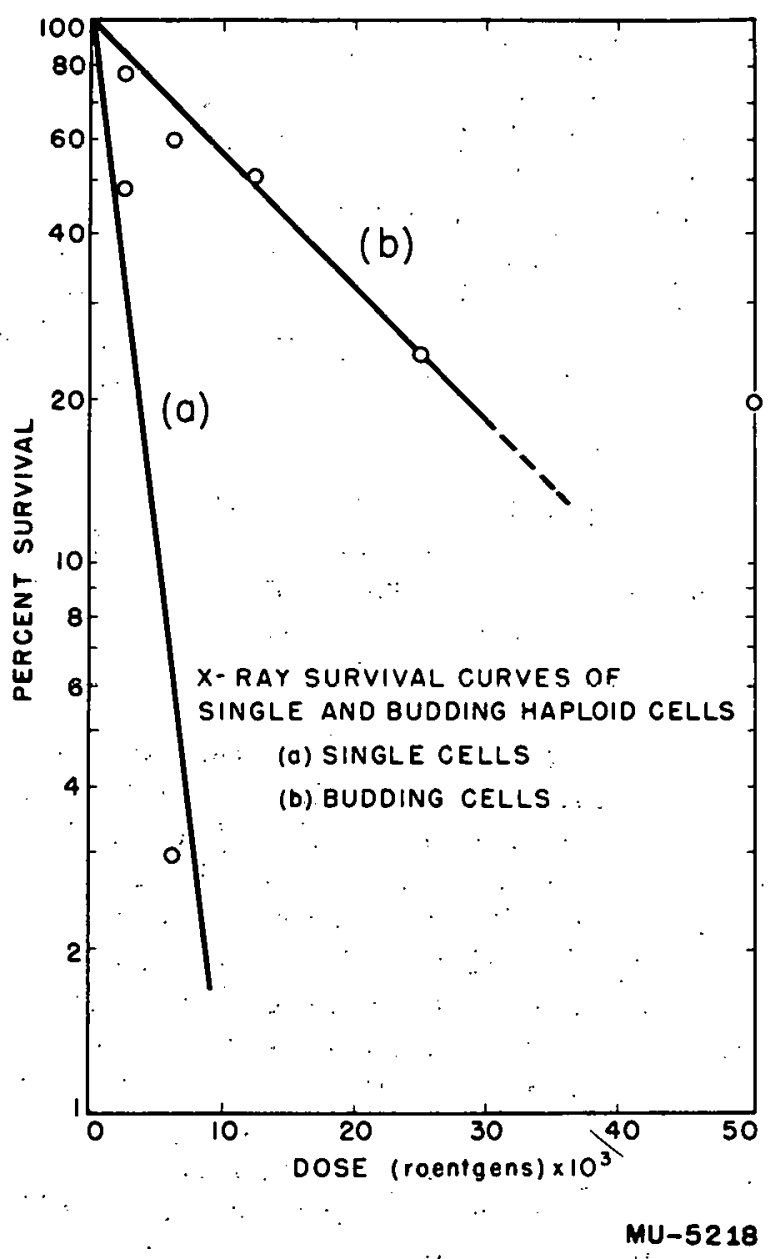

Fig. 3 


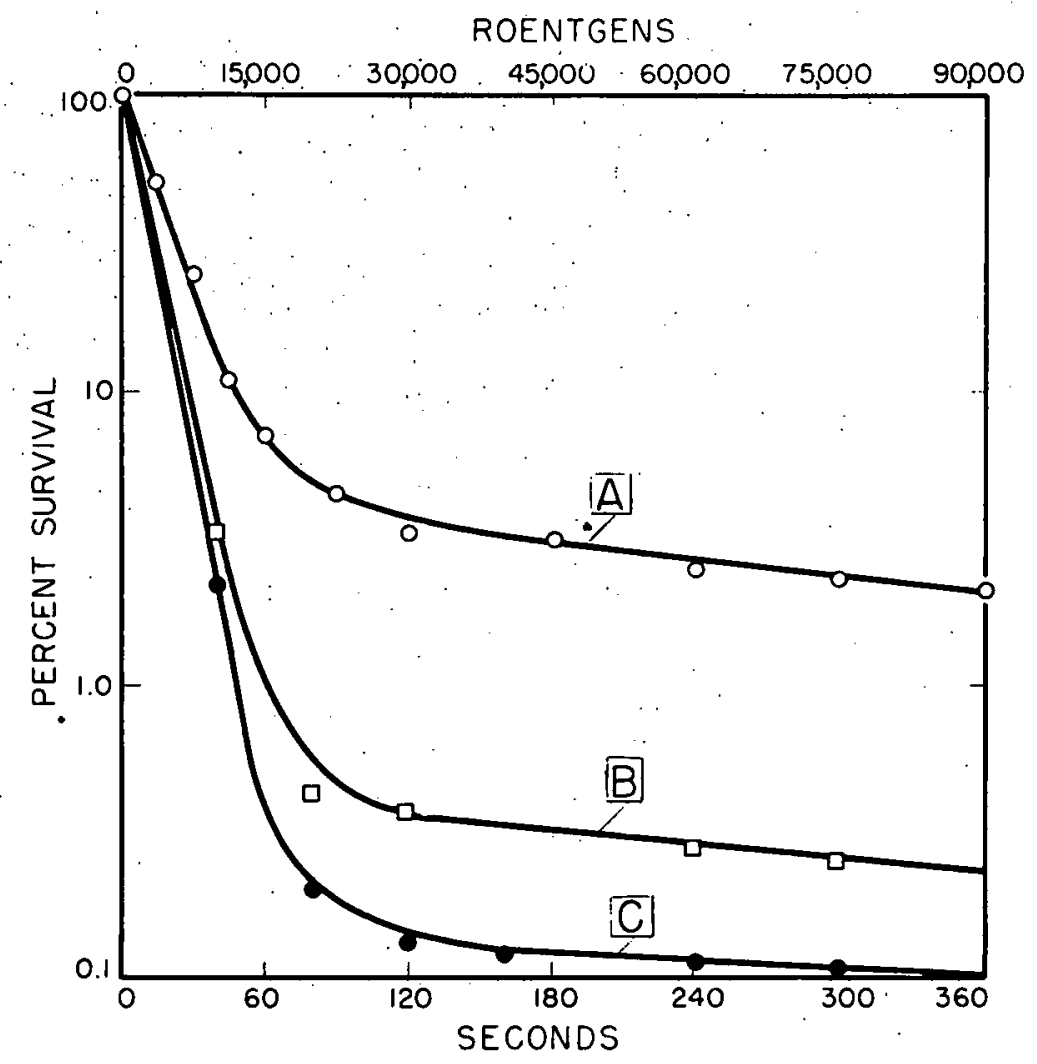

MU-5339

Fig. 4 The $x$-ray survival of hxploid yeast during the course of nitrogen staivation in buffered 2 percent dextrose at $30^{\circ} \mathrm{C}$

A The survival curve of unstarved cells

$B$ ifter 6 hours' starvation

C. After 20 hours' starvation 


\section{2}

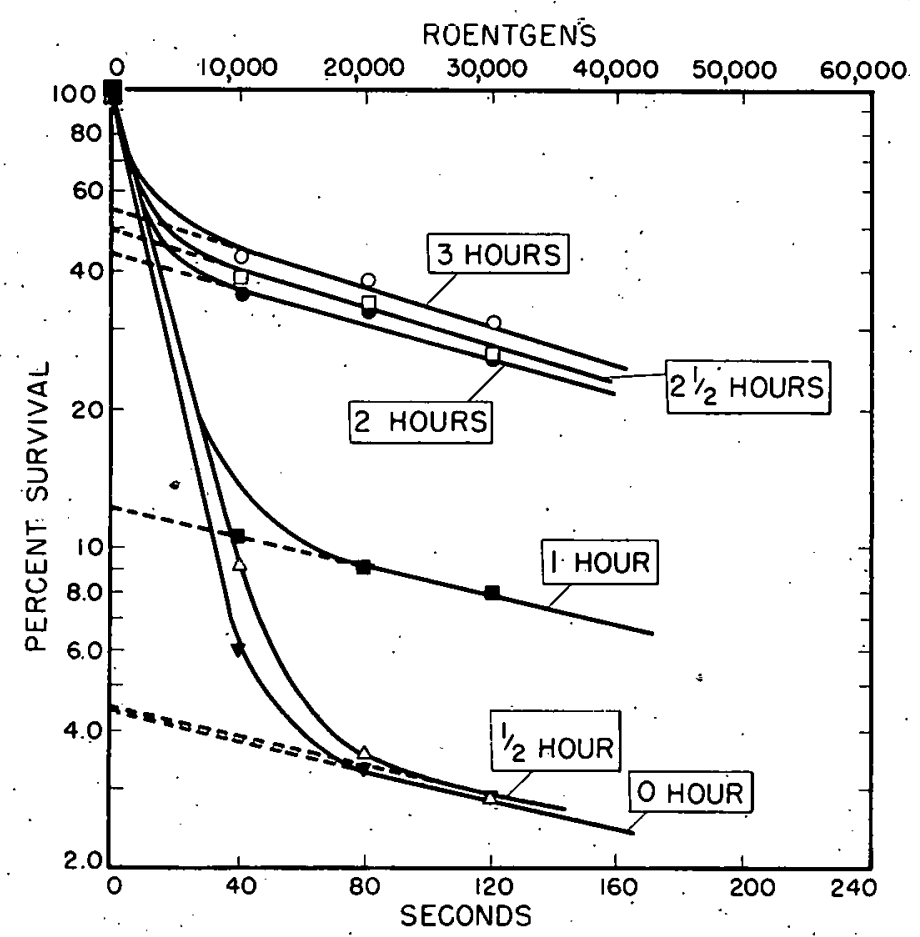

Fig. 5. The x-ray survival of starved haploid yeast after various periods of incubation from 0 to 3 hours on fresh yeast. extract dextrose agar. Back extripolations of the resistant components of the survival curves are made to provide estimations of the percentage of radio-resistant cells in the populitions. 


\section{3}

\begin{tabular}{|c|c|c|}
\hline $\begin{array}{c}\text { HOURS ON } \\
\text { YE D } \\
\text { MEDIUM,30C }\end{array}$ & $\begin{array}{l}\text { PERCENT } \\
\text { OBSERVABLE } \\
\text { BUDS }\end{array}$ & $\begin{array}{l}\text { PERCENT } \\
\text { RADIO-RESISTANT } \\
\text { CELLS }\end{array}$ \\
\hline 0 & 7.3 & 5.3 \\
1 & 13 & 12 \\
$1 \frac{1}{2}$ & 23 & 45 \\
2 & 32 & 50 \\
$2 \frac{1}{2}$ & 54 & 53 \\
\hline 3 & 59 & \\
\hline
\end{tabular}

Table I Correlation of the percentage of buds with the percentage of radioresistant cells (fxorn Fig. 5) in populations of stirved calls after virious periods of incubation on fresh yeast extrict dextrose agax. 
The relation of nuclear division to radioresistance has recently been reviewed by Sparrow. 12 In most of the biological materials, both plant and animal, upon which such studies have been made, cells in the process of division, especially those between prophase and metaphase, are much more radiosensitive than those in other stages. Our results with yeast suggest that in these cells prophase represents a stage of high radioresistance. Although the death of yeast cells may involve more than chromosome breaks (the usual parameter in such studies), our results emphasize the possibility of a wide range of variability among organisms in the relation of radiosensitivity to stage in cell division.

The protracted survival curves of haploid yeast (Fig. 1) are reminscent of some reported for Escherichia coli strains $B$ and $B / r, 13$ and it is possible that $a$ s in $B / \mathrm{r}^{14}$ the high radioresistance of dividing yeast cells may be correlated with a high DNA content. The high target multiplicity exhibited in the survival of dividing cells (Fig. 1) could signify a high degree of replication of "sensitive sites" 3 at some stage of the division process which is restored after division to the normal.

There is not enough information for exact mathematical description of the survival curve of dividing cells, but an approximate fit can be made to the expression $N=N_{0}\left[1-\left(1-e^{-a D}\right)^{m}\right]^{n_{i}, 3}$ where $m$ is the degree of replication and $n$ is the number of sensitive sites, if $m \times n$ is about 1000 .

Other possibilities, of course, exist. The high resistance of dividing yeast cells could arise by a type of intranuclear chemical protection during division such that many masking molecules must be destroyed before a "sensitive

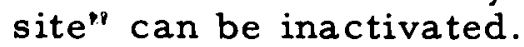

It is hoped that by improving the starvation procedure it will be possible to produce a more homogeneously resting population of cells, which should possess, therefore, a higher degree of synchrony in the first poststarvation division. Under such conditions the shift in radiosensitivity associated with the onset of nuclear division could be made the subject of detailed biochemical and biophysical investigation.

yeast $4,6,8$ Of interest is the fact that ultraviolet survival curves on haploid radioresistant component corresponding to the budding cells. Nor is the shape of the ultraviolet survival curve simplified by starvation procedures effective on the resistant component of the $\mathrm{x}$-ray curves. 4

It is of practical importance to note that the variation in sensitivity of yeast cells during the course of cell division brings into question the use of LD $50^{\prime} \mathrm{s}$ for predicting or evaluating the effectiveness of chronic low-level irradiation on biological systems in which cells undergo proliferation.

Summary and Conclusions

The $\mathrm{x}$ - ray survival of haploid yeast is established as consisting typically of two components, an initial exponential of $\mathrm{LD}_{50}=3100 \mathrm{r}$, which represents the survival of about 90 percent of a population of growing cells, and a complex multiple-hit component which represents that of the remainder $\left(L_{50}=90,000 \mathrm{r}\right)$. 
The ability of clumps, occasional diploids, or a distribution of radiosensitivities to account for this complex radioresistant component is eliminated.

Evidence that the radioresistant component represents the survival of budding yeast cells comes from two sources. The first, experiments in which the $x$-ray survival of single and budding cells was followed microscopically, showed the budding cells to be much more radioresistant than the resting ones. The second employed cells which had been incubated in a buffered dextrose solution in the absence of nitrogen. Under these conditions division ceases, and, as the starvation proceeds, the level of the radioresistant component of the survival curve decreases. If extended sufficiently, nitrogen starvation can produce a population essentially homogeneous (99.999 percent) with respect to radioresistance: When fresh nutrients are added to starved cells, the onset of fresh budding is in approximate synchrony $(60$ percent) and is accompanied by a corresponding reappearance of the radioresistant component of the $x$-ray survival curve.

The high radioresistance of dividing yeast cells may be associated with gene multiplicity during division or with unique biochemical properties of the nucleus at this time. 


\section{REFERENCES}

1. D. E. Lea, Actions of Radiation on Living Cells, New York, The Macmillan Company, 1947.

2. R. Latarjet and B. Ephrussi, C.R. Acad. Sci., Paris; 224, 3061949.

3. R. Zirkle and C. A. Tobias, Effects of Ploidy and Linear Energy Transfer

- on Radiobiological Survival Curves, Arch. Biochem. and Biophys. (in press).

4. C. A. Beam; Studies on the Killing of Microorganisms by/Chemical and Physical Agents, Ph. D. Thesis, Yale University, 1950.

5. A. Lacassagne and F. Holweck, C. R. Soc. de Biol., 104, 1221 (1930):

6. R. K. Mortimer, Cytological and Environmental Factors Related to the Effects of Radiations on Yeast Cells, Ph.D. Thesis, University of California, 1953.

7. C. A. Tobias and B. Stepka, University of California Radiation Laboratory Report No. UCRL-1922, 1952.

8. R. Latarjet, Address given at the International Joint Commission on Radiobiology, Stockholm, Sweden, 1952.

9. C. A. Beam, R. K. Mortimer, and C. A. Tobias. Unpublished.

10. T. H. Wood, Influence of Temperature on X-Ray Sensitivity of Haploid Yeast Cells, Ph. D. Thesis, The University of Chicago, 1953.

11. E. D. Delamater, J. Bact., 60, 321-332 (1950).

12. A H. Sparrow, Ann. New York Acad. Sci., 51, 1508 (1951).

13. V. Bryson, J. Bact., 56, 423-433 (1948).

14. M. L. Morse and C. F. Carter, J. Bact., 58, 317-326 (1949). 


\title{
THE LIQUID SCINTILLATION COUNTING OF TRITIUM - AND C ${ }^{14}$ - LABELED COMPOUNDS
}

\author{
Donald J. Rosenthal t and Hal O. Anger
}

\begin{abstract}
Following the studies reported by Kallman and Furst on the transfer of energy in solutions, 1,2 great interest. was aroused in the liquid-scintillator counting of radioactivity. In the past few years, many varied applications of this technique have been described in the literature. As part of the program of metabolic research being conducted at this laboratory, low-energy beta emitters have been employed as tracers, and it was decided to investigate the use of the liquid-scintillator counter in the measurement of their specific activities. It is the purpose of this paper to describe an instrument we have developed whereby the very low energy beta particles emitted by $\mathrm{H}^{3}$ and $\mathrm{C}^{14}$ may be counted with relative ease, rapidity and accuracy, using equipment available in nearly all laboratories measuring radioactivity.
\end{abstract}

Apparatus

Figure 1 is a drawing of the basic unit of the counter--the photomultiplier tube, its preamplifier, the lighttight sample holder, and the surrounding lead shield. This equipment is placed on the floor of a 7 -cubic-foot lid-opening deep freeze unit fitted with an adjustable temperature control.

The photomultiplier tube (Dumont $\mathrm{K}-1177$ ) was chosen because of its very high signal-to-noise ratio. It has a cesium-antimony photocathode with a window area of 1.8 square inches, and an S-9 spectral response, with maximum sensitivity at about $4800 \AA$. The preamplifier is a 3 -tube unit, with a gain of 30 , and input sensitivity of about 3 millivolts when used with the scaler described below. It is built into the small chassis which holds the photomultiplier tube socket in order to reduce the pickup of extraneous electrical. interference. A cathode follower furnishes a low-impedance output circuit to further reduce interference.

The leads from the preamplifier are carried out of the freeze unit directly to a scale-of-256 scaler, designed at the Radiation Laboratory for use with scintillation counters. It has an input sensitivity of 0.1 volt. The input amplifier of the scaler, and the preamplifier, are stabilized in gain by means of negative feedback. The high"voltage required for the multiplier tube is obtained from a regulated variable power, supply built into the scaler, and is applied across a conventional voltage-divider network connected to the phototube. The signal is taken from the next to last dynode, since the scaler preamplifier requires a positive input pulse.

The inner surface of the aluminum sample holder has the shape of a truncated cone, and is coated with several smooth layers of white Tygon enamel, so as to reflect as much of the light as possible down towards the photocathode. The vessels that actually contain the scintillator solution are 3 -dram polyethylenestoppered capsule vials. Because of their low cost, and to avoid contamination problems, these vials are used for only one sample, and then discarded. The

*Postdoctorate Research Fellow of the National Heart Institute. 
vials have a slightly concave bottom surface, and are optically coupled to the slightly convex window of the photomultiplier tube by means of a medium-viscosity silicone fluid.

Materials

The tritiated stearic acid used to test the counter was prepared as described previously. 3 Its specific activity was determined by the ionizationchamber method, standardized against $\mathrm{H}^{3}$. gas samples originally measured at Argonne National Laboratory and diluted manometrically in our laboratory. The $C^{14}$-labeled cholesterol was prepared by biosynthesis, and its specific activity was assayed by the ionization-chamber system, calibrated with a National Bureau of Standards sample of $\mathrm{C}^{14}$-barium carbonate.

All the organic solvents and scintillators used in this study were of the ordinary commercial reagent grade, and were not further purified.

\section{Experimental}

Figure 2 shows the effectiveness of cooling the photomultiplier tube in reducing the thermal noise background. The actual tube temperatures are $10^{\circ}-15^{\circ} \mathrm{C}$. higher than those shown in the figure, owing to heat produced in the preamplifier and conducted up into the tube by the electrical contacts.

The counting efficiency for the tritium beta particles and radiation background varied only a fraction of a percent over the temperature range studied. The thermal noise background rate, however, was reduced to one-sixth its value at room temperature by placing the counter in an environmental temperature of $10^{\circ} \mathrm{C}$. Below this temperature, the decrease in thermal noise per degree reduction in temperature is very much less; when the instrument is operated below $10^{\circ} \mathrm{C}$. it is relatively insensitive to small temperature fluctuations.

According to Wouters, 4 the sharp rise in the thermal noise curve in the region $10^{\circ}-25^{\circ} \mathrm{C}$. is due to the presence in the tube, at this latter temper ature, of cesium vapor molecules. Cooling the tube reduces the vapor pressure of the cesium sufficiently to abolish this phenomenon, and thermionic emission from the cathode is then the predominant cause of the tube noise. 5

The counting rates obtained when known amounts of $\mathrm{H}^{3}$-labeled stearic acid or $\mathrm{C}^{14}$-labeled cholesterol were added to aliquots of seven different liquidscintillator solutions are shown in Table $\mathbb{I}$. The most efficient solutions were the xylene-terphenyl-diphenylhexatriene and phenylycyclohexane-terphenyl-diphenylhexatriene solutions. Benzene freezes at $5.50 \mathrm{C}$., but it is of interest to note that a relatively good counting rate was obtained with this solvent even though the sample was solidly frozen and no longer transparent. However, for routine use, frozen samples are unsuitable, since their translucency varies with the rate of freezing.

Because we are primarily interested in counting labeled lipids, solubility studies were carried out to see which of the above-mentioned scintillator solutions was the better solvent for fatty acids and cholesterol. The xylene solution dissolved 2 to 3 times as much fatty acid as did the phenyl-cyclohexane, at $-20^{\circ} \mathrm{C}$. To confirm the results obtained in the preceding experiment, since it has been reported that terphenyl in xylene is a poor scintillator for use at. 
reduced temperatures owing to its insolubility, 6 a solution was prepared containing $5 \mathrm{~g} / 1$ terphenyl in xylene, with $0.015 \mathrm{~g} / 1$ diphenylhexatriene added. Aliquots were stored at $20^{\circ}, 0^{\circ},-10^{\circ}$, and $-30^{\circ} \mathrm{C}$. for two days. Some terphenyl did crys tallize out of solution at the lower temperatures, but when identical amounts of tritium activity were added to $4-\mathrm{ml}$ portions of the supernatants, the decrease in counting rate with the weaker solutions was less than 10 percent. Judging from the curve of the relative intensity of fluorescent light vs. concentration of terphenyl in xylene, reproduced in Kallman's paper, ${ }^{1}$ this result is to be expected, since the slope of the curve. is quite small between concentrations of 3.5 and $5.0 \mathrm{~g} / 1$.

All the subsequent experiments were done with the xylene-terphenyldiphenylhexatriene solution, prepared as described above, but allowed to stand at $-10^{\circ} \mathrm{C}$. for several days. After the crystals were removed, the solution was stored at room temperature: The freezing unit was set to maintain a temperature of $-10^{\circ} \mathrm{C}$.

No intensive study of the various scintillator poisons was carried out. However, Table II shows the effect on the counting rate of the additions of nonradioactive stearic acid or cholesterol. Neither of these substances is a potent quenching agent. Alcohol did not decrease the counting rate either, but carbon tetrachloride completely quenched the scintillations, even in very low concentrations ( 2 drops per $4 \mathrm{ml}$ of scintillator).

Figure 3 shows the counting rates obtained for $\mathrm{H}^{3}$ and $\mathrm{C}^{14}$ samples of equal activity as the photomultiplier tube voltage was varied. The maximum. efficiency for tritium, 49 percent, was obtained at 1500 volts, but the background count was $2,680 \mathrm{cpm}$. At 1300 volts, the efficiency for tritium was 33 percent, and the background was only $630 \mathrm{cpm}$. At this voltage, the instrument has about the same sensitivity and background level for counting $\mathrm{H}^{3}$ as the ionization-chamber method. Owing to the more energetic beta particles from $\mathrm{C}^{14}$, the efficiency of the counter for $\mathrm{C}^{14}$ is much higher. Efficiencies approaching 100 percent were recorded with background rates of about $150 \mathrm{cpm}$; and 60 percent efficiency was accompanied by a background count of only $45 \mathrm{cpm}$. The slight increase in the C14 curve above 1050 volts, where the apparent efficiencies are greater than 100 percent, is due to double pulsing. The tritium beta particles produce pulses which are of low amplitude. The more energetic $\mathrm{C}^{14}$ radiation, however, produces pulses which are so much higher that, when the tube is being operated above a certain gain setting (1050 volts in this case), a poor transient response in the amplifier results in doubling of some of the pulses. When $P^{32}$ was counted, this phenomenon of double pulsing was present at tube voltages higher than 950 volts. However, double pulsing does not occur with:tritium samples at any voltage up to 1500 volts. It must be pointed out, then, that no one voltage setting will serve for the counting of all the different radioactive isotopes.

To study the accuracy of the counter, a group of samples was prepared containing known quantities of tritiated stearic acid of high specific activity (11. 7 microcuries $/ \mathrm{mg}$ ). The weakest sample contained $1.46 \times 10^{-3}$ microcuries, and the most active one had $5.86 \times 10^{-2}$ microcuries of the active stearic acid. Figure 4 is a plot of the counting rate vs. the volume of the standard radioactive fatty acid solution used to prepare the sample. The maximum deviation from the expected counting rate was 1.5 percent. 
Table I

Relative Efficiencies of Scintillator Solutions

Solution

Efficiency of counting (percent)

A) Samples contained $\mathrm{C}^{14}$-labeled cholesterol $(7,200 \mathrm{dpm})$. Counter at $18^{\circ} \mathrm{C}$.

Benzene - terphenyl ( $5 \mathrm{~g} / 1)$

Dioxane - terphenyl $\therefore(5 \mathrm{~g} / \mathrm{l})$

Xylene - terphenyl . (5 g/1)

Xylene - terphenyl

Phenylcyclohexane - terphenyl $(3 \mathrm{~g} / 1)$ diphenylhexatriene $(0.015 \mathrm{~g} / 1)$

B) Samples contained $\mathrm{H}^{3}$-labeled stearic acid $(32,500 \mathrm{dpm})$. Counter at $20 \mathrm{C}$.

$\begin{array}{lr}\text { Benzene - terphenyl }(5 \mathrm{~g} / 1) * & 22.5 \\ \text { Xylene - terphenyl }(5 \mathrm{~g} / 1) & 24.3 \\ \text { Xylene - terphenyl }(5 \mathrm{~g} / 1)- & 29.8 \\ \text { diphenylhexatriene }(0.015 \mathrm{~g} / 1) & 23.5 \\ \text { Phenylcyclohexane - terphenyl }(3 \mathrm{~g} / 1) & \\ \text { Phenylcyclohexane - terphenyl }(3 \mathrm{~g} / 1)-\cdots & 29.1\end{array}$

C) Samples contained $\mathrm{H}^{3}$-labeled stearic acid $(32,500 \mathrm{dpm})$. Counter at $-20^{\circ} \mathrm{C}$.

Xylene - terphenyl. (5 g/1) diphenylhexatriene $(0.015 \mathrm{~g} / 1)$

Benzene - terphenyl $(5 \mathrm{~g} / \mathrm{I}) *$

Benzene - terphenyl (5 g/l) -

3.9

diphenylhexatriene $(0.015 \mathrm{~g} / 1) *$

10.6

* Sample was solidly. frozen. 
Table II

Effect of Addition of Nonradioactive Stearic Acid or Cholesterol on the Counting Rate of a Tritiated Fat Sample.

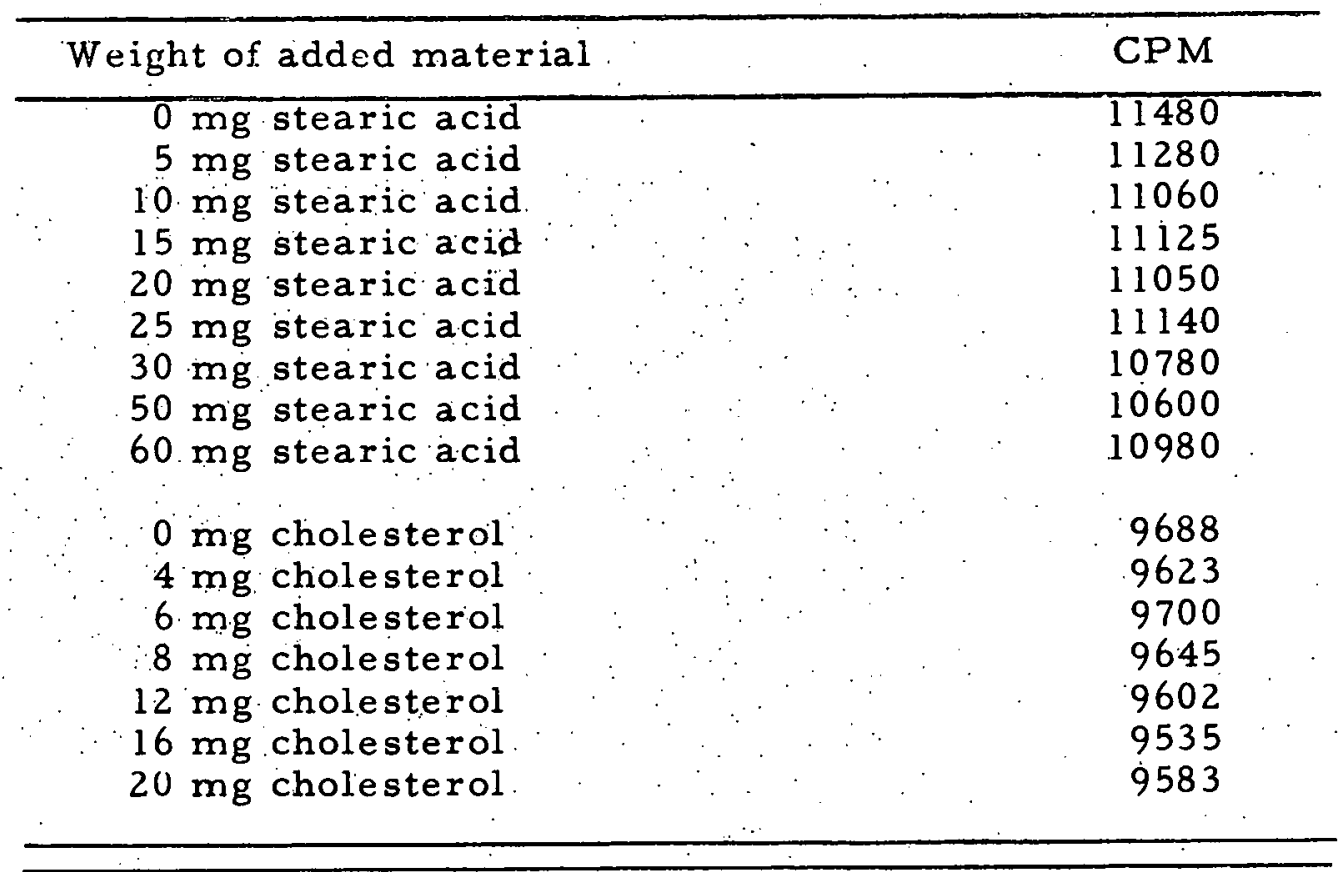

Table III

Effect on Counting Rate of Volume of Liquid Scintillator.*

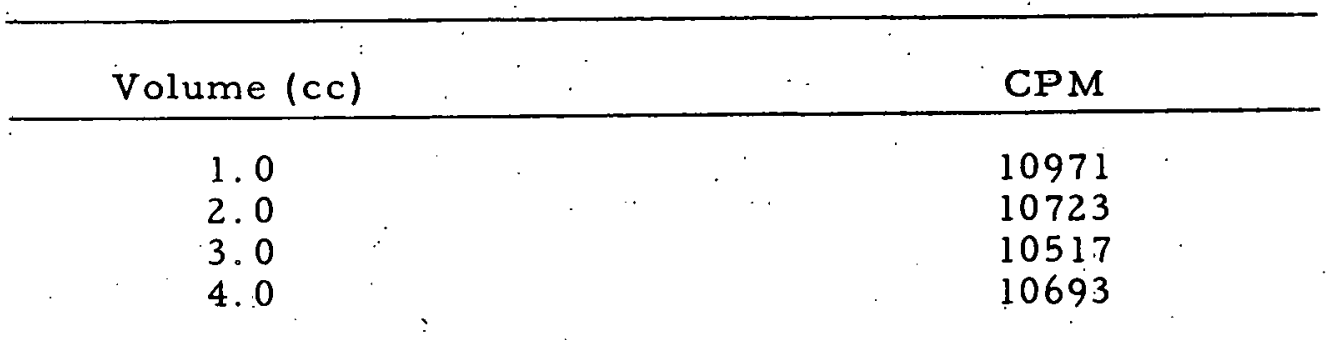

* One sample used for all four measurements. Xylene-terphenyl-diphenylhexatriene scintillator. 


\section{Table IV}

Effect of Concentration of Diphenylhexatriene.*

\begin{tabular}{|c|c|}
\hline Concentration & CPM \\
\hline $\begin{array}{l}0.015 \mathrm{~g} / 1 \\
0.030 \mathrm{~g} / 1 \\
0.060 \mathrm{~g} / 1\end{array}$ & $\begin{array}{l}8774 \\
8808 \\
8820\end{array}$ \\
\hline
\end{tabular}

* Same tritium activity in all 3 samples. Basic. solution was xylene-terphenyl (4 g/1). 
Figure 5 is a frequency histogram of the distribution of 244 successive 90 -second counts of a weak tritium sample, together with a superimposed normal curve. A special count-rate recorder ${ }^{7}$ was connected to the sicaler output to obtain these data. The theoretical standard deviation, using the formula $\sigma=$ $\sqrt{(\mathbb{N} / t)}$; was 1.65 . The value calculated from the actual frequency distribution was 1.635. To check on the stability of the scaler over a longer period of time, and also to ascertain the reproducibility of the whole counting process, including the introduction of the sample into the counter, one sample was counted 50 times in six weeks. The standard deviation of the set of measurements thus ob-tained was 2 percent.

Table III shows the effect of varying the volume of liquid scintillator solution added to the samples. The relatively small change in counting rate with a fourfold increase in volume indicates that absorption of the emitted light by the solution itself is small, and that the reflector is quite efficient. The concentration of diphenylhexatriene is not critical either, as shown by the results in Table IV.

Since the need frequently arises to count tritium-labeled water or water-soluble compounds, it was thought desirable to explore this use of the counter. With the method suggested by Hayes 8 as a basis, it was found that good counting efficiencies. could be obtained if a 5 percent solution of the water or aqueous solution were made up in absolute ethanol, and $1 \mathrm{ml}$ of the alcoholic solution mixed with $3 \mathrm{ml}$ of the liquid scintillator. Table $\mathrm{V}$ shows the counting rates obtained from serially diluted tritium water samples, using this method of achieving miscibility of the water and xylene. Lower alcohol concentrations resulted in layering of the solutions when they were cooled to the temperature of the phototube. Higher concentrations of the alcohol solution in the final sample, such as $2 \mathrm{ml}$ of the 95 percent alcohol solution with $2 \mathrm{ml}$ of the scintillator, resulted in a reduced counting rate due to the decrease in the effective volume of the scintillator.

Finally, to determine whether the good results obtained with the counter in measuring the activity of weak beta particles were due to the inadvertent selection of an unusually good photomultiplier tube, the performance characteristics of four tubes were compared. Figure 6 is a plot of counting rate vs. voltage applied to the tube when the same standard tritium-sample and background counting rates were measured at varying voltages, with all four tubes. The similarity of the curves is quite striking, and any of the tubes would serve satisfactorily in the counter.

Discussion

Until the liquid scintillation counter was developed, the standard technique for measuring tritium activities in this laboratory was the ionization chamber-vibrating reed electrometer method described previously. 9 While this method usually gives satisfactory results, preparation of samples is difficult and time-consuming. A vacuum system, with all the troubles inherent therein, is needed to fill the chambers. Also, during the combustion process, or the reduction of the water vapor to hydrogen by passage over hot zinc, enough of the tritium exchanges with the hydrogen atoms in the glass of the containers so that "memory" effects are noted. Since it is usually necessary to keep the ionization chambers on the electrometer for at least an.hour to get an accurate 
Table V

Tritium Water Counting. *

\begin{tabular}{crrr}
\hline Activity in sample & & CPM*** & Efficiency \\
\hline $29,450 \mathrm{dpm}$ & $4,6,00$ & $:$ & $15.6 \%$ \\
$14,725 \mathrm{dpm}$ & 2,355 & $16.0 \%$ \\
$7,360 \mathrm{dpm}$ & 1,203 & $16.3 \%$ \\
$3,680 \mathrm{dpm}$ & 588 & $16.0 \%$ \\
\hline
\end{tabular}

* Sample preparation described in text.

**Background of $640 \mathrm{cpm}$ already subtracted. 
count, the number of samples that can be counted in a day with one instrument is quite small. At very low levels of activity, the accuracy and precision of the method are quite poor. Lastly, the cost of the chambers, vibrating-reed electrometer, and recording potentiometer is usually prohibitive for the average isotope laboratory.

The liquid-scintillator method of counting has none of these disadvantages. Preparation of most of the samples requires only that a known weight of the active material be placed in a sample vial. The scintillator is then added, the vial carefully agitated to dissolve all the solid material, and after a few hours of cooling in the deep freeze, the sample is ready for counting. The saving in time and equipment is considerable. Although the length of time required for counting depends on the desired accuracy, it is usually possible to count 20 to 30 samples in an eight-hour day with one instrument. The stability of the counting efficiency and background are such that the error in counting samples whose activity is equal to, or as low as, half the background counting rate depends, for the most part, on the length of time one counts the sample, and not on pecularities of the counter itself (as is the case with the ionization chambers we have used). "Memory." effects are avoided by using the sample vials only once. Lastly, the major components are available commercially, and are relatively inexpensive.

There are several precautions which must be observed when using this type of counter, however. The color the the liquid-scintillator solution must not be altered by the material which is to be dissolved in or mixed with it for counting. The emission spectrum of the xylene-terphenyl-diphenyl-hexatriene solution lies between 3200-4800 Angstroms. Part if not all of this radiation would be absorbed by any substance that produces a colored solution when dissolved in the scintillator. As reported by Kallman, 2 the other efficient scintillator solutions have very similar emission spectra, and therefore using them would not alter the situation.

The second precaution which must be taken is to be certain that the sample to be counted does not contain a scintillator "poison". These systems are susceptible to quenching by a wide variety of organic substances, presence of which would obviously preclude the use of this counting method. It is a relatively simple matter to ascertain their presence, however.

Finally, the samples must be precooled and kept in the dark before they are counted. If a sample at room temperature is placed on the window of the photomultiplier tube, it will warm it and raise the background count temporarily. In addition, if the sample has been exposed to bright light before being placed in the counter, the initial counting rate will be in error owing to phosphorescence of the liquid scintillator. Both of these difficulties can be resolved by placing the samples in the freezing unit several hours before they are to be counted, and having the room but dimly illuminated whenever the freezer lid is open.

This counter, as employed by us, has an absolute counting efficiency of 33 percent for fat-soluble tritium-labeled compounds, with a background counting rate of about $600 \mathrm{cpm}$. In spite of the seemingly high background, the sensitivity is about twice that obtained with the ionization-chamber method. An ionization chamber containing $7.5 \times 10^{-10}$ curies of tritium. will produce, on our vibrating-reed electrometer, a reading just equal to the average background rate. This same amount of activity, when counted by the liquid scintillation method 
as described above, will also give a counting rate that approximates the background value. However, activities equal to half the background rate may be accurately counted by the liquid scintillation counting method, but this is not true for the ionization chambers.

When counting tritium-labeled water samples, the scintillation counter . is not as efficient as when measuring materials that are soluble in the scintillator. The final sensitivity in this case is about equal to that of the ionization-chamber method.

For counting $\mathrm{C}^{14}$-labeled compounds that are soluble in the scintillator solution, the efficiency of the counter can be varied from 30 percent to nearly 100 percent, depending on the background rate most suitable for the level of activity contained in the samples. This liquid-scintillation method is not more efficient than the standard ways of counting $\mathrm{C}^{14}$ at equivalent background rates. However, the technique of sample preparation for scintillation counting is much more simple and rapid than those required for the gas or solid counting of $\mathrm{C}^{14}$.

\section{Summary}

Utilizing the liquid-scintillation principle of counting, a relatively simple counter for very weak beta particles has been developed. The counter is stable. accurate, and more sensitive than the ionization chamber-vibrating reed electrometer method of measuring tritium, and, for the same time interval, allows one to count many more samples than with the chamber method.

The main features of the instrument are the use of an efficient liquidscintillator solution, and a photomultiplier tube that has a very high signal-tonoise ratio, and which is also cooled to further reduce the noise background.

The method is suitable for counting $\mathrm{H}^{3}$ or $\mathrm{C}^{14}$-labeled compounds that are soluble in the ordinary fat solvents, and which do not color or quench the scintillator solution. Tritium-labeled water or aqueoüs solutions of tritiumlabeled compounds can also be counted with good efficiency if they are first mixed with absolute ethanol. Samples are prepared for counting by merely dissolving them in or mixing them with the liquid-scintillator solution.

The apparatus required is relatively inexpensive and uncomplicated, and is available commercially. 


\section{REFERENCES}

1. H. Kallman and M. Furst, Phys: Rev. 79, 857 (1950).

2. H. Kallman and M. Furst, Phys. Rev. 81, 853 (1951).

3. D. Rosenthal and D. Kritchevsky, UCRL-1331.

4. L. Wouters, UCRL, Personal Communication.

5. R. W. Engstrom, Jour. Opt. Soc. Am., 37, 420 (1947).

6. F. N. Hayes, R: D. Hiebert, and R. L. Schuch, Science, 116, 140 (1952).

7. H. O. Anger, Nucleonics $8,76(1951)$.

8. F. N. Hayes and R. G. Gould; Science 117, 480 (1953).

9. M. W. Biggs, D. Kritchevsky, and M. R. Kirk; Anal. Chem. 24, 223 (1952). 


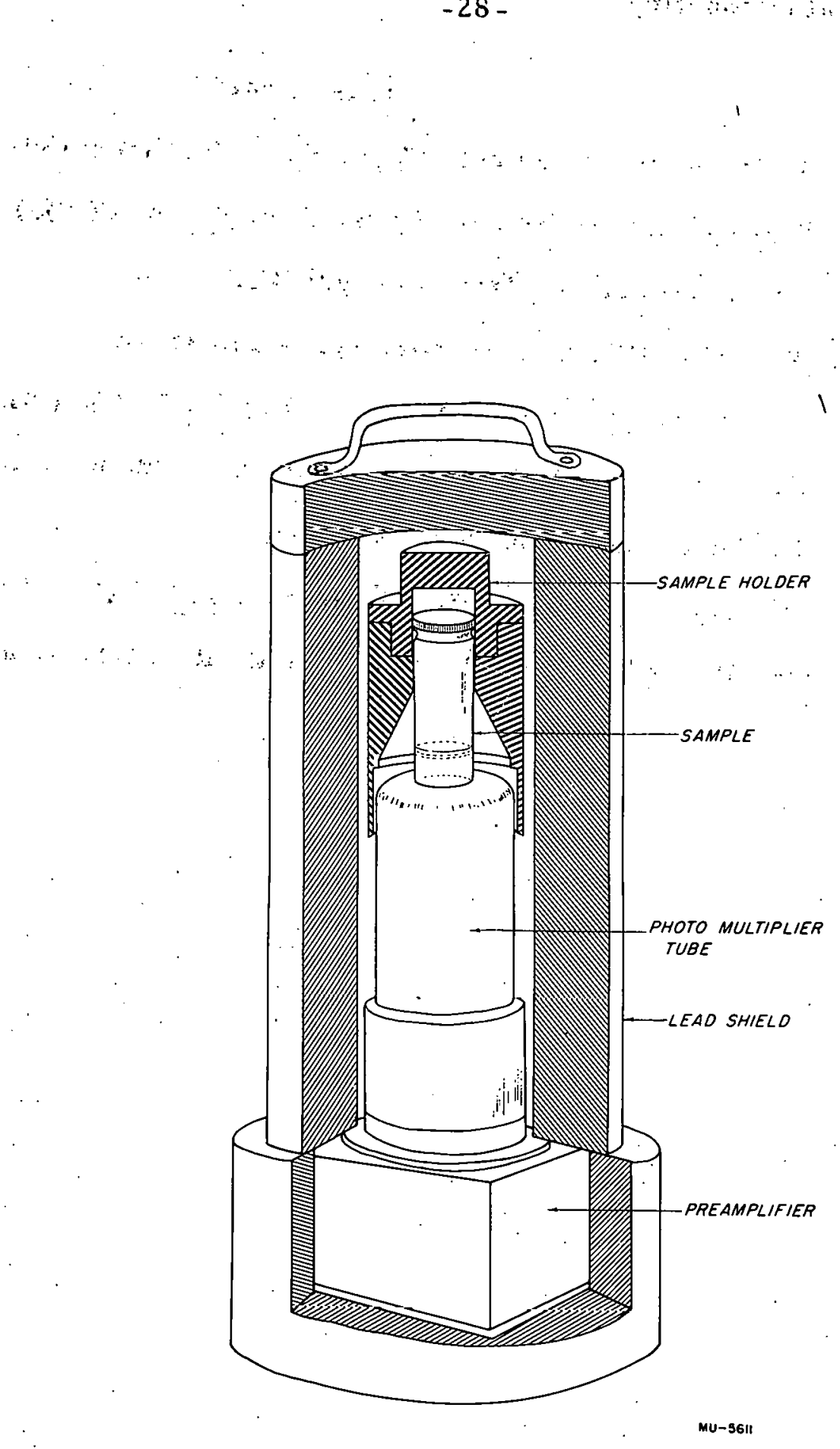

Fig. 1 Driwing showing arrangement of photomultiplier tube, sample vial, sample holder, and preamplifier within the radi2tion shicld. 


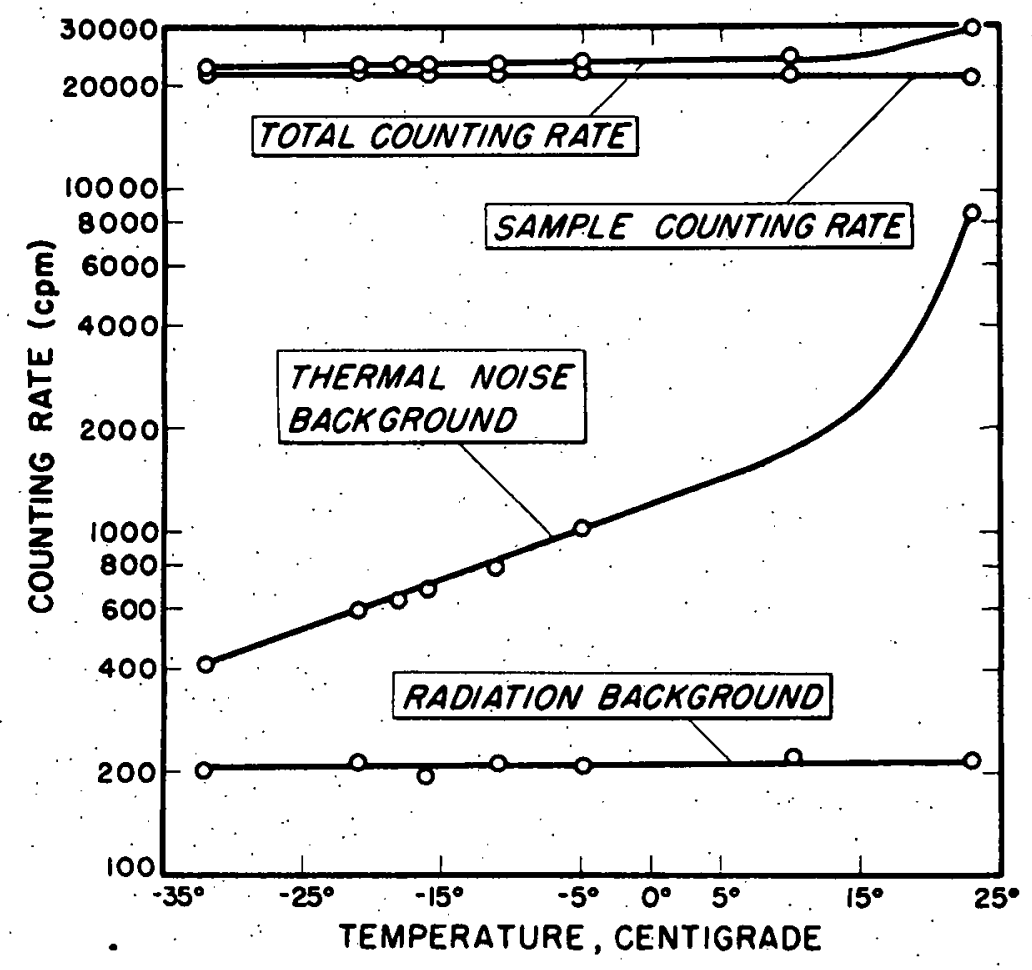

MU-5977

Fig. 2. Gruph of counting rates obtained with onc stindard tritiated stearic acid sample as the temperature of the freezing unit containing the counter is varied. 


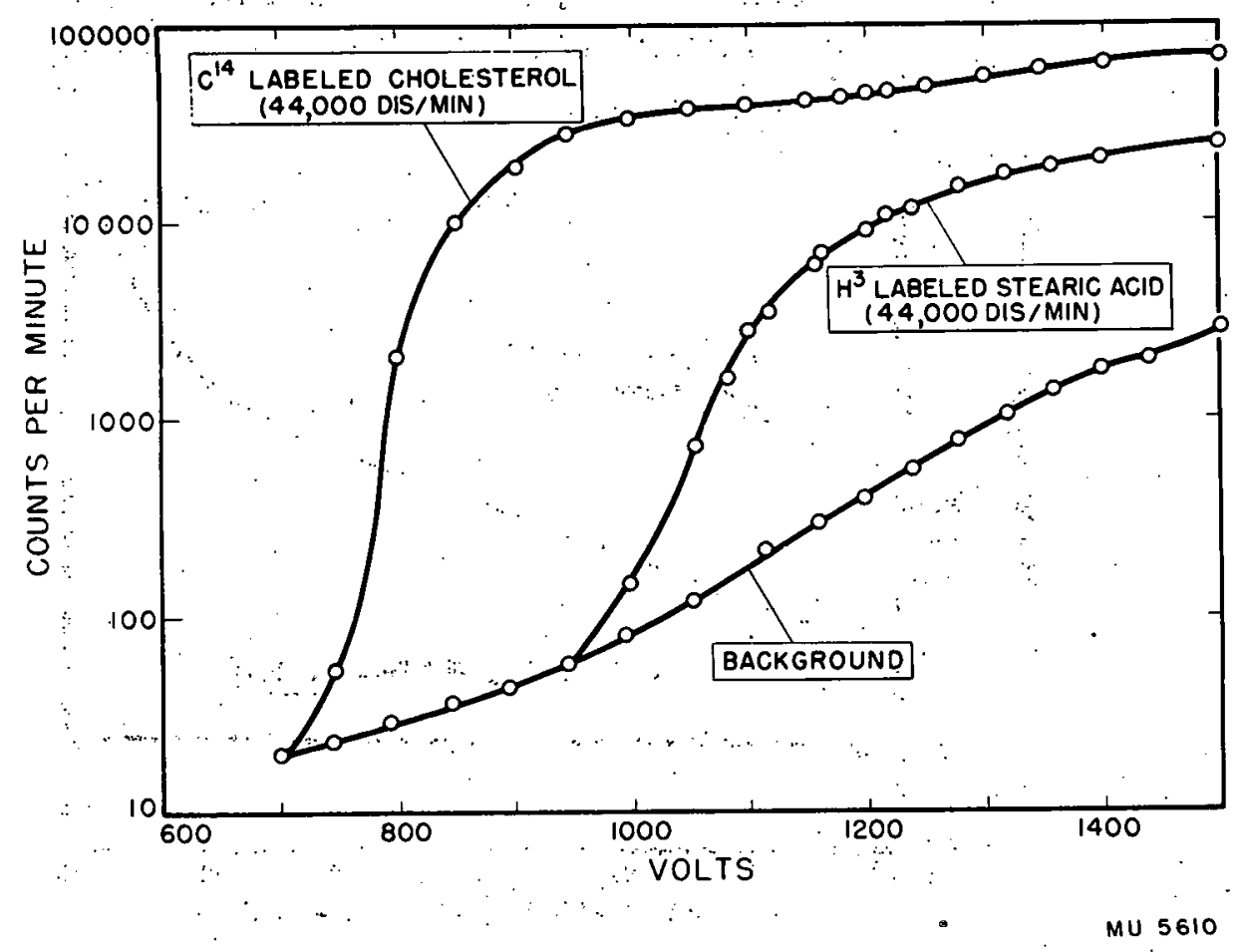

Fig. 3 Plot of counting rates of $\mathrm{C}^{14}$ - and $\mathrm{H}^{3}$-containing samples of equal activity as a function of the voltage applied to the photomultiplier tube: Xylene-terphenyl-diphenylhexatriene scintill ator. 


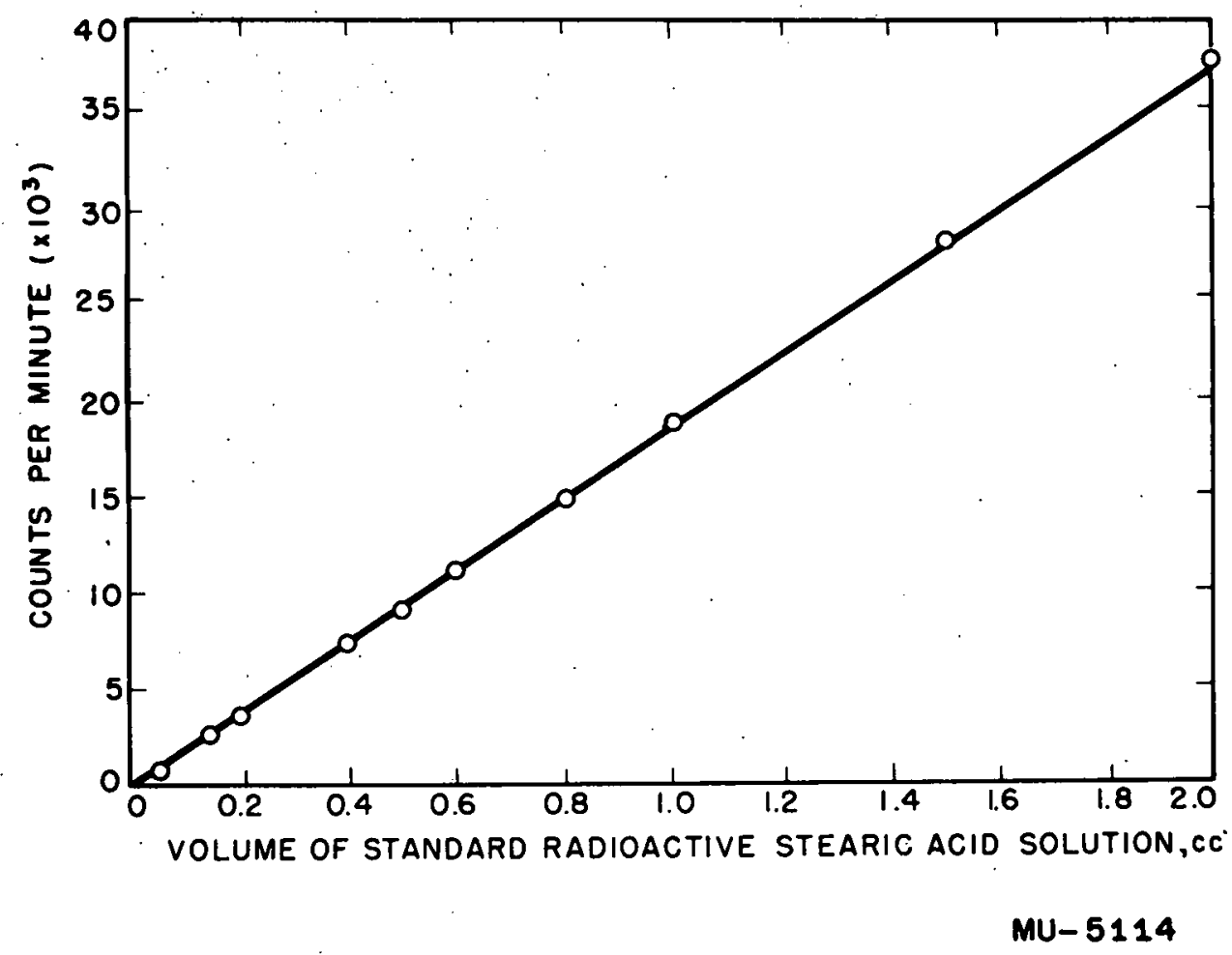

Fig. 4 Plot of the counting $r$ te shtined for a series of tritiumlabeled samples prepared bymezsuring out different volum is of a standird tritiated stearic solution, and then evaporating the solvent. Xylene-terphanyl-diphenylhexatriene scintillitor. 


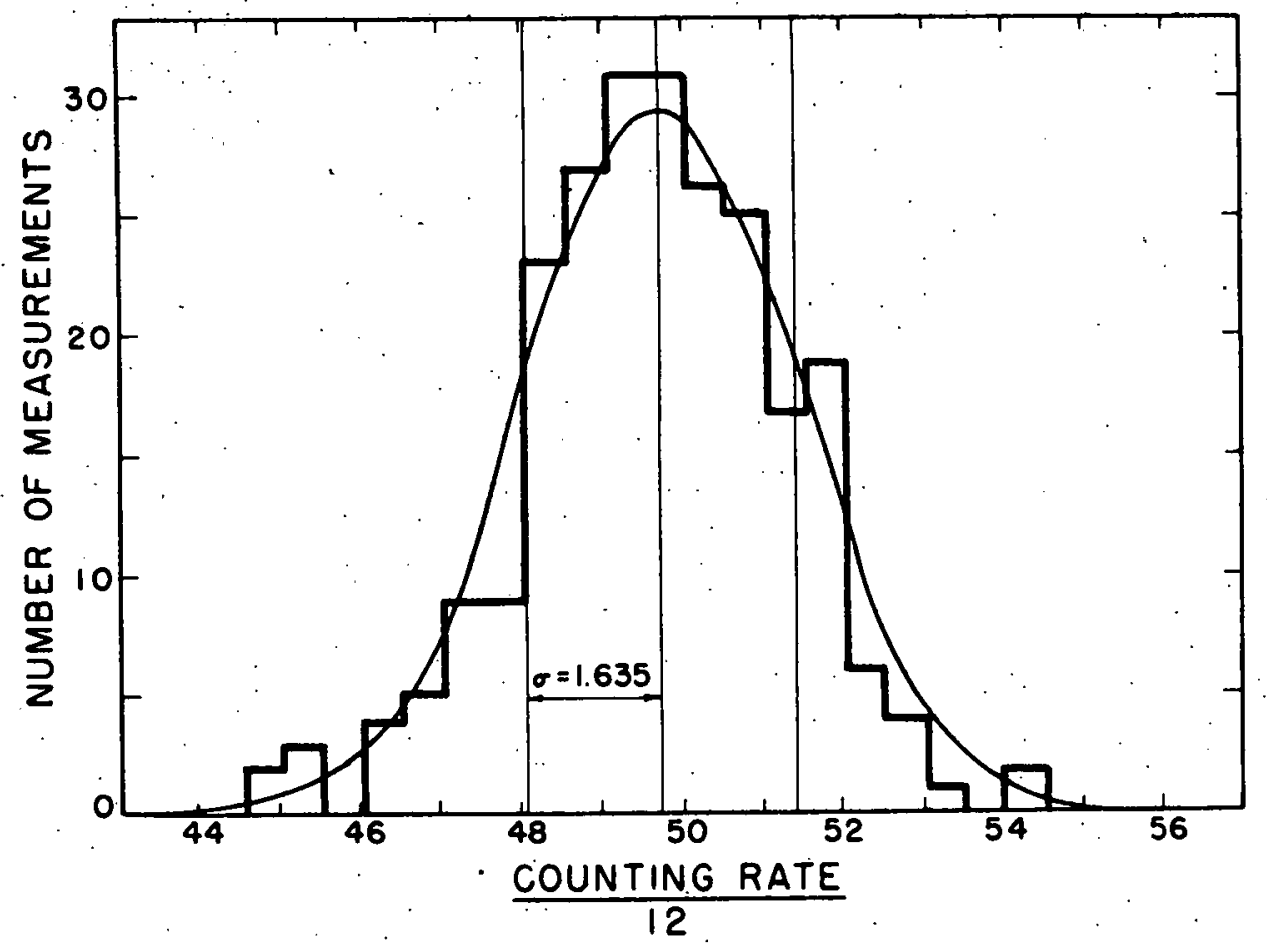

MU-5113

Fig: 5 Histogrim of the distribution of 244 successive counts of one tritiated fatty acid sample. Smooth curve is the normal curve obtained from the datt. 


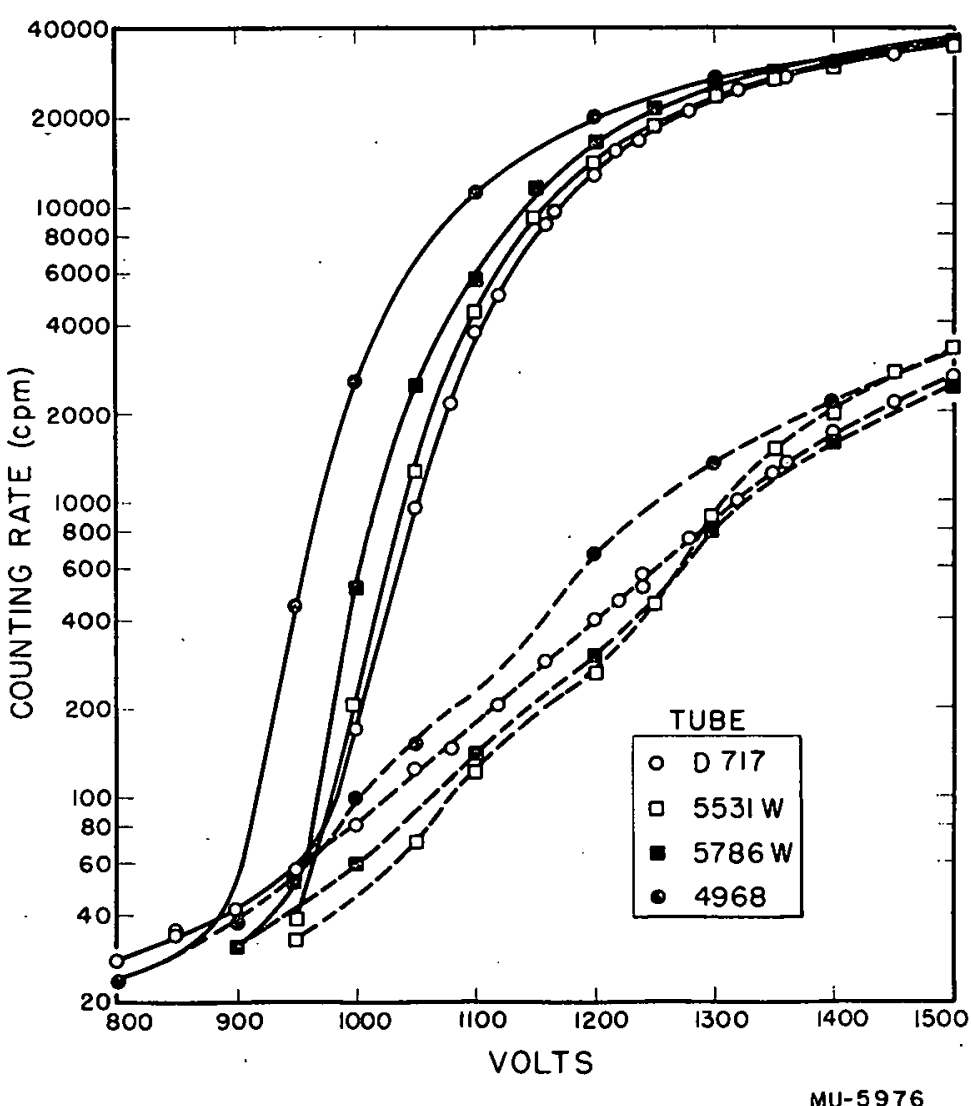

Fig. 6 Curves obtained when one sample (containing $61,000 \mathrm{dpm} \mathrm{H}^{3}$ ) ind background were counted by four different photomultiplier tubes, at varying tube voltages. Folid line = Simple counting rite; dashed line = Background rate. Tube no. $5786 \mathrm{~W}$ is a Dumont type 6292 tube; the others are Type K 177 tubes. 


\section{THE METABOLIC PROPERTIES OF VARIOUS MATERIALS}

Joseph G. Hamilton, M.D.

\section{TRACER STUDIES}

\section{ASTA TINE IN RATS AND MONKEYS}

\section{J. G. Hamilton and Marshall Parrott}

The different leukocyte counts have now been completed for the first astatine experiment described in the previous quarterly report. The rats received 0.76 microcuries of $\mathrm{At}^{211}$ per gram and there was a calculated dose of $135 \mathrm{rep}$, assuming uniform distribution and neglecting excretion. These animals also received a tracer dose of radiosodium and were sacrificed two days after receiving the astatine. These data for the blood counts may be seen in Table I. In this, there are included the red cell and total white cell counts.

The red cell, white cell and differential counts for the second experiment, for which astatine was employed with a dose level of 0.73 microcuries per gram, gave a calculated value of 140 rep assuming the conditions indicated in the first of the two astatine studies. These rats received radiosodium tracer as well, and were sacrificed two days after receiving astatine. The results may be seen in Table II. The profound leukopenia produced as a result of the treatment of astatine is evident in both tables. There was an apparant increase in the number of granulocytes at the end of two days. This effect is somewhat mis - . leading inasmuch as the lymphocytes dropped much more rapidly than the granulocytes and this drop produced a relative increase in granulocytes expressed in terms of absolute number of cells.

Two additional monkeys each received two millicuries of astatine by intraperitoneal injection during this quarter, and the dose was calculated to be 145 rep for animal number 1 and 137 rep for animal number 4. Their weight, total white cell counts and differential counts are being followed as much as is possible. Red cell counts will also be done. The other two animals previously treated during the last quarter will be maintained. The additional data concerning the first group of two monkeys, each of which received 0.96 millicuries of $\mathrm{At}^{211}$ per gram may be seen in Table III. Comparative data for the second group of animals appear in Table IV. From the previous report there may be seen quite a marked leukopenia, and three days with a moderate degree of lymphopenia. Slight recovery appeared in both groups within 10 days, but after reaching a value of approximately one-third of that of the control animals the total white count has remained nearly the same.

Four female rats were sacrificed which had received approximately $0.70 \mathrm{microcurie}$ per gram of astatine by intraperitoneal injection nearly a year ago. These animals were Sprague-Dawly strain, 60 days of age, and their werght at the time of intraperitoneal injection was approximately $125 \mathrm{grams}$, and the calculated dose was $125 \mathrm{rep}$. One day before these rats were sacrificed each received radioiodine by intraperitoneal injection for investigation of the microscopic deposition of radioiodine in what was presumably severely damaged 


\section{5}

Table I

Differential Counts of 7 Rats Each of Which Received 1.5 Microcuries of At 211 per Gram of Body Weight by Intraperitoneal Injection and Were Sacrificed 2 Days Later. Blood Counts Were Taken I Day Prior to Administration of At ${ }^{211}$ and at the Time of Sacrifice. A Comparison for the Control Values May Be Noted from Table II. There are Included as a Matter of Interest Total Red Cell and White Cell Counts.

\section{Treated Group}

\begin{tabular}{|c|c|c|c|c|c|c|c|c|c|c|}
\hline \multirow[t]{2}{*}{ Rat } & \multirow{2}{*}{$\begin{array}{l}\text { RBC } \\
-1 \text { day }\end{array}$} & \multirow{2}{*}{$\begin{array}{l}\text { Millions } \\
\text { per mm } \\
2 \text { days }\end{array}$} & \multirow{2}{*}{$\begin{array}{l}\text { WBC } \\
-1 \text { dày }\end{array}$} & \multirow{2}{*}{$\begin{array}{c}\text { Thousands } \\
\text { per } \mathrm{mm}^{3} \\
2 \text { days }\end{array}$} & \multicolumn{2}{|c|}{$\begin{array}{c}\% \text { of } \\
\text { lymphocytes }\end{array}$} & \multicolumn{2}{|c|}{$\begin{array}{c}\% \text { of } \\
\text { granulocytes }\end{array}$} & \multicolumn{2}{|c|}{$\begin{array}{c}\% \text { of } \\
\text { monocytes }\end{array}$} \\
\hline & & & & & -1 day & 2 days & -1 day & 2 days & -1 day & 2. days \\
\hline 1 & 7.06 & 6.34 & 6.80 & 1.45 & 90.4 & 27.6 & 9.6 & 71.6 & - & 0.8 \\
\hline 2 & 6.74 & 5.48 & 9.85 & 1.10 & 85.0 & 24.0 & 15.0 & 74.8 & - & 1.2 \\
\hline 3 & 4.91 & 5.27 & 13.20 & 0.85 & 96.4 & 36.2 & 3.6 & 62.2 & - & 1.6 \\
\hline 4 & 5.93 & 6.09 & 12.25 & 1.55 & 97.6 & 7.4 & 2.6 & 92.6 & - & - \\
\hline 5 & 5.09 & 5.37 & 9.70 & 0.75 & 99.2 & 23.6 & 0.6 & 75.8 & 0.2 & 0.6 \\
\hline 6 & 6.25 & 5.03 & 12.35 & 0.85 & 85.4 & 24.0 & 14.6 & 74.0 & - & 2.0 \\
\hline 7 & 5.68 & $\underline{5.54}$ & 10.50 & 2.70 & 93.6 & 40.0 & 6.4 & 57.8 & - & 2.2 \\
\hline rage & 5.95 & 5.59 & 10.70 & 1.32 & 92.5 & 26.1 & 7.5 & 72.7 & - & 1.2 \\
\hline $\begin{array}{l}\text { n Stdd. } \\
\text { eror }\end{array}$ & \pm 0.31 & \pm 0.17 & \pm 0.60 & \pm 0.26 & \pm 2.3 & \pm 4.0 & \pm 2.7 & \pm 4.2 & - & \pm 0.3 \\
\hline
\end{tabular}




\section{6}

Table II

Differential Counts of 6 Rats Each of Which Received 0.83 Microcuries of At 211

Per Gram of Body Weight by Intraperitoneal Injection and Were Sacrificed 5 Days

Later. Blood Counts Were Taken 1 Day Prior to the Administration of At 211 and

at the Time of Sacrifice. Similar Values are Included for the 6 Control Animals.

There are Included as a Matter of Interest the Total Red Cell and White Cell

Counts.-

\section{Control}

\section{RBC}

Rat millions $/ \mathrm{mm}^{3}$ thousands -1 day 2 day 5 day -1 day 2 day 5 day
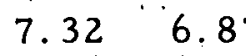

6.87

6.50

7.06

6.50

6. 10

6.48

7. 6.4

6. 72

7. 40

7.40

$\begin{array}{lll}6.50 & 14.45 & 18.20\end{array}$

11.40

$5.78 \quad 17.35$

13.10

3.90

$\begin{array}{lll}5.15 & 9.30 & 16.15\end{array}$

7.15

$\begin{array}{lll}6.24 & 14.30 & 16.25\end{array}$

$\begin{array}{lll}5.80 & 9.80 & 9.75\end{array}$

6.30
5.10

14.72

7.8494 .0

$\%$ of lymphocytes

-1 day 2 day 5 day

$\%$ of granulocytes -1 day 2 day 5 day

88.6

83.2

78.8

9. 2

14.418 .2

$94.6 \quad 83.0$

95.8

87.0

94.6

97.4

97.8

95.6

90.4

95.6

82.8

93.4

89.0

91.4

3.0

2. 2

4.2

7.4

10.8

4.2

9.2

3.6

5.0

9.8

2.2

2.2

16.8

5.8

8

$\begin{array}{lllllllllllll}\text { Mean } & \pm 0.21 & \pm 0.14 \pm 0.05 & \pm 1.27 & \pm 1.20 & \pm 1.50 & \pm 1.3 & \pm 1.95 & \pm 3.5 & \pm 1.1 & \pm 2.1 & \pm 3.1 & \pm 0.3 \quad \pm 0.3 \quad \pm 0.2\end{array}$
$\%$ of monocytes -1 day 2 day 5 day

2.2

1.2

1.2

0.4

0.2

0.4

$2.4 \quad 3.0$

0.6

2.2

1. 2

0.4

0.8

0.91 .3

0.4

0

0.4

0.8 Error

\section{Treated}

Rat millions/m -1 day 2 day 5 thousands $/ \mathrm{mm}^{3}$

$$
\begin{aligned}
& 6.16 \\
& 6.20 \\
& 7.38 \\
& 7.25 \\
& 7.10 \\
& 6.81
\end{aligned}
$$

\begin{abstract}
$\begin{array}{lll}7.31 & 5.40 & 13.35\end{array}$
$6.84 \quad 5.80 \quad 15.65$

$\begin{array}{llll}6.16 & 6.34 & 10.15\end{array}$

$6.95 \cdot 6.00 \quad 22.25$

$\begin{array}{lll}6.56 & 6.05 & 12.35\end{array}$

6.97

11.60
\end{abstract}

$6.80 \quad 5.92 \quad 14.2$

$\pm 0.19 \pm 0.15 \pm 0.14 \pm 1.8$

Std.

Error

WBC

1.35

1.05

.95

1.27

5 day

$\%$ of lymphocytes -1 day 2 day 5 dầy

$\%$ of granulocytes -1 day 2 day. 5 day

0.650 .55

95.0

21.8

94.7

4.0

77.6

3.. 0

87.5

97.0

13.8

0.55

97.6

15.8

$96: 9$

1.4

1.2

0.95

95.4

26.8

93.0

92.7

0.43

96.3

92.9

$\pm 0.19 \pm 0.10$
17.0

$3.0 \quad 81.9 \quad 5.0=$

$\pm 0.2 \pm 2.5 \quad \pm 0.2 \pm 0.6$
85.0

$84: 2$

9.4

2. 0

$70.6 \cdot 7.3$

$5.0=$

$\pm 2.4 \pm 1.2$
$\%$ of monocytes -1 day 2 day 5 day

$\begin{array}{lll}1.0 & 0.6 & 2.3\end{array}$

$\begin{array}{lll}0.2 & 0.2 & 2.3\end{array}$

$\begin{array}{lll}0 & 1.2 & 3.1\end{array}$

$1.2-1.1$

$\begin{array}{lll}1.4 & 2.6 & 0.7\end{array}$

$\begin{array}{lll}0.8 & 0.6 & 1.6\end{array}$

0.8

$0.9 \quad 1.85$

$\pm 0.2 \pm 0.4 \pm 0.4$ 


\section{Table III}

The Leukocyte and Differential Count of 2 Monkeys Which Received At 211 2-17-53. Each Animal Received 0.96 Millicuries of $\mathrm{At}^{211}$ by Intraperitoneal Injection. Animal Number 2 Weighed 2.8 Kilograms at the Time of Injection, and Animal Number 5, 2.6 Kilograms. For Each Differential Count 500 Leukocytes Were Counted. Animals Number 3 and 6 Served as Controls.

\section{Monkey. WBC Differential WBC, \% of 200}

Date Days Number Total $/ \mathrm{mm}^{3}$ Lympho. Neutro. Eosino. Baso. Mono.

\begin{tabular}{|c|c|c|c|c|c|c|c|c|c|}
\hline Cont. & $4 / 10$ & 52 & $\begin{array}{l}3 \\
6\end{array}$ & $\begin{array}{l}14,450 \\
15,450\end{array}$ & $\begin{array}{l}41.5 \\
65.9\end{array}$ & $\begin{array}{l}56.0 \\
32.9\end{array}$ & $\begin{array}{l}2.0 \\
1.2\end{array}$ & - & $\begin{array}{c}0.5 \\
-\end{array}$ \\
\hline Exper & & - & $\begin{array}{l}2 \\
5\end{array}$ & $\begin{array}{l}6,400 \\
5,550\end{array}$ & $\begin{array}{l}64.0 \\
86.5\end{array}$ & $\begin{array}{l}30.0 \\
12.5\end{array}$ & $\begin{array}{l}5.0 \\
1.0\end{array}$ & - & $\begin{array}{c}1.0 \\
-\end{array}$ \\
\hline Cont. & $4 / 24$ & 66 & $\begin{array}{l}3 \\
6\end{array}$ & $\begin{array}{l}11,850 \\
13,500\end{array}$ & $\begin{array}{l}74.0 \\
71.0\end{array}$ & $\begin{array}{l}19.0 \\
27.0\end{array}$ & $\begin{array}{l}7.0 \\
2.0\end{array}$ & - & - \\
\hline Exper. & & & $\begin{array}{l}2 \\
5\end{array}$ & $\begin{array}{l}4,150 \\
5,350\end{array}$ & $\begin{array}{l}71.5 \\
77.5\end{array}$ & $\begin{array}{l}26.0 \\
21.5\end{array}$ & $\begin{array}{l}0.5 \\
0.5\end{array}$ & - & $\begin{aligned}= & 2.0 \\
& 0.5\end{aligned}$ \\
\hline Cont. & $5 / 15$ & 87 & $\begin{array}{l}3 \\
6\end{array}$ & $\begin{array}{l}17,300 \\
14,850\end{array}$ & $\begin{array}{l}76.5 \\
80.0\end{array}$ & $\begin{array}{l}23.0 \\
18.0\end{array}$ & - & - & $\begin{array}{l}0.5 \\
0.5\end{array}$ \\
\hline Exper. & & & $\begin{array}{l}2 \\
5\end{array}$ & $\begin{array}{l}8,180 \\
6,800\end{array}$ & $\begin{array}{l}38.5 \\
72.0\end{array}$ & $\begin{array}{l}60.0 \\
27.5\end{array}$ & $\begin{array}{c}1.0 \\
-\end{array}$ & $\begin{array}{l}0 \\
-\end{array}$ & $\begin{array}{l}0.5 \\
0.5\end{array}$ \\
\hline Cont: & $5 / 29$ & 101 & $\begin{array}{l}3 \\
6\end{array}$ & $\begin{array}{r}14,200 \\
3,450\end{array}$ & $\begin{array}{l}60.5 \\
74.0\end{array}$ & $\begin{array}{l}37.0 \\
23.5\end{array}$ & $\begin{array}{l}2.0 \\
2.5\end{array}$ & - & $\begin{array}{c}0.5 \\
-\end{array}$ \\
\hline Exper. & & & $\begin{array}{l}2 \\
5\end{array}$ & $\begin{array}{l}6,150 \\
3,900\end{array}$ & $\begin{array}{l}69.0 \\
71.0\end{array}$ & $\begin{array}{l}29.5 \\
27.5\end{array}$ & $\begin{array}{l}1.0 \\
1.0\end{array}$ & - & $\begin{array}{l}0.5 \\
0.5\end{array}$ \\
\hline
\end{tabular}


Table IV

Two Additional Monkeys Each Received 2 Millicuries of $\mathrm{At}^{21 \mathrm{l}}$ by Intraperitoneal Injection. Animal Number 1 Weighed 2. 4 Kilograms and Animal Number 4, 2.6 Kilograms at the Time of Injection Which was 5-19-53. For Each Differential Count 500 Leukocytes Were Counted.

\section{Monkey WBC Differential WBC, \% of 200}

Date Days Number Total $/ \mathrm{mm}^{3}$ Lympho: Neutro. Eosino. Baso: Mono.

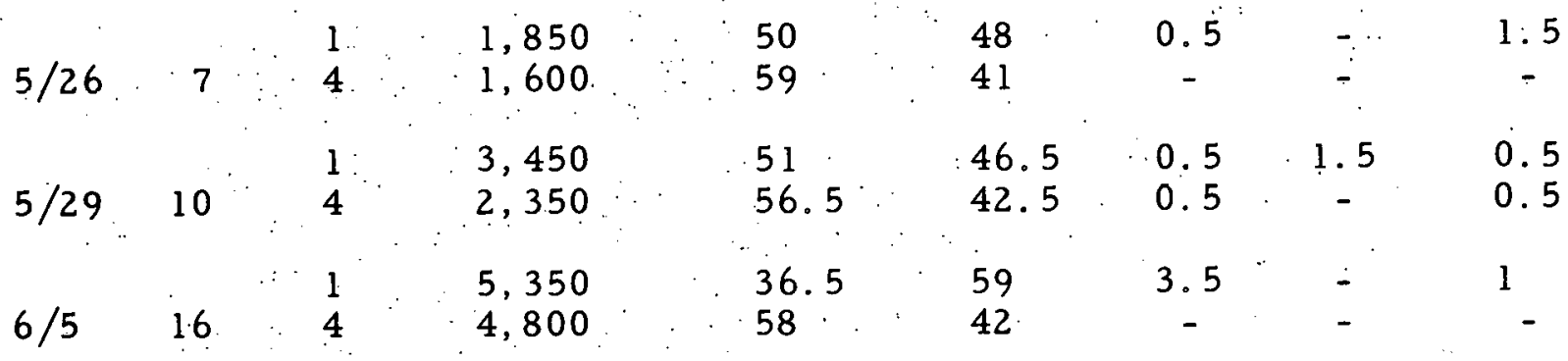


thyroid tissue. The weight of the four rats and the percent of accumulated radioiodine may be seen in Table V. Under the environmental conditions and diet at which these and other rats are maintained in this laboratory, 20 percent of the administered dose of radioiodine is normally retained by the thyroid gland at 24 hours. In addition to the radioiodine uptake studies, roentgenograms were taken of these-four animals in an attempt to determine the bone age. Aside from the thyroid gland a number of other tissues and organs were removed at the time of sacrifice and these included heart, muscle; lacrimal gland, salivary gland, pituitary gland, liver, kidney, adrenal, spleen, ovary, small intestine, lymph nodes, thymus and skin. These tissues are now being worked up for histological. study.

In order to evaluate more effectively the long-term changes of astatine in the rat, larger groups of 60-day-old Sprague-Dawly female rats were given astatine at levels of $1.0 \mu \mathrm{c}, 0.75 \mu \mathrm{c}$, and $0.5 \mu \mathrm{c}$ per gram. In each group and in the control group there are 10 animals. 


\section{Table V}

The Accumulation of Radioiodine by the Thyroid Gland of Each of 4 Rats Which Had Received 1 Microcurie per Gram of Astatine 1 Year Previously; The Radioiodine Was Given 1 Day Before the Animals Were Sacrificed.

\begin{tabular}{|c|c|c|c|}
\hline Rat Number & Weight & $\%$ of Accumul & ation of Radioiodine \\
\hline 1 & $126 \mathrm{~g}$ & & 0.009 \\
\hline 2 & $190 \mathrm{~g}$ & $\therefore$ & 0.005 \\
\hline 3 & $138 \mathrm{~g}$ & $\because$ & 0.04 \\
\hline 4 & $198 \mathrm{~g}$ & $\therefore$ & 0.17 \\
\hline
\end{tabular}




\section{RADIOGRAPHIC STUDIES OF SKELETONS OF ASTA TINE - TREATED MONKEYS}

C. W. Asling and J. G. Hamilton

Radiographs have been obtained of representative regions of the skeleton of a normal male monkey ("Mischief") whose estimated age, approximately 3 years, accords closely with that of the astatine-treated monkey ("Ferdie") recently sacrificed and reported upon. The latter monkey has been diagnosed as having been chronically and severely hypothyroid. (See Histology Section of Quar terly Progress Report, January-March, 1.953). The present radiographs support the previous diagnosis of retarded bony development of the treated monkey. Details of the comparison are as follows:

1. The proximal epiphysis of the humerus remains open (Fig.1) as in the treated monkey.

2. The distal epiphysis of the humerus is fully closed (Fig. 2). It was partly open in the treated monkey.

3. The olecranon epiphysis of the ulna is fully expanded and its epiphyseal cartilage is narrowed (Fig. 2). The treated monkey showed a small epiphysis with a wide cartilage.

4. In the forepaw (Fig. 3) the signs of more advanced bone age than was seen in the treated animal are:

1. Metacarpal ephiphyses II-V are fusing or have recently fused.

2. A carpal (radial) sesamoid bone has developed.

3. A sesamoid bone has developed under the distal end of the first metacarpal.

5. The ossification center of the tibial tuberosity has appeared (Fig. 4). This was lacking in the treated animal. In the popliteal fossa two sesamoids are seen, in contrast to one in the treated animal.

6. In the hindpaw a tarsal sesamoid has developed laterally, metatarsals III and IV show partial epiphyseal fusion, and an additional sesamoid has developed under the distal interphalangeal space of the hallux (Fig. 5). It is also convenient to estimate the growth retardation from the lengths of such long. bones as may be measured. Two are sampled here.

\begin{tabular}{|c|c|c|c|}
\hline Bone & \multicolumn{2}{|c|}{ Length in Millimeters } & $\begin{array}{l}\% \text { Retardation In } \\
\text { Treated Monkey }\end{array}$ \\
\hline Metacarpal III & 35.1 & 25.3 & $28 \%$ \\
\hline Metatarsal III & 49.8 & 34.6 & $30 \%$ \\
\hline
\end{tabular}

As will be seen, the retardation of growth agrees closely in the two bones. The slight differences probably result from technical errors, such as parallax in the shadows cast by the $x$-ray. 


\section{FIGURE CAPTIONS}

Figures 1 to 5 inclusive. Reproductions, natural size, of radiographs of selected regions of skeleton of normal male monkey of age estimated at 3 years: Grateful acknowledgement is made of the assistance of Dr. Gertrude Van Wagenen, of Yale University, in providing age ranges for the various ossification centers, the figures for which are given in parentheses..

Fig. 1 Shoulder; open epiphyseal line of humerus at $\mathbf{x}(21 / 2$ to $31 / 2$ years).

Fig. 2 Elbow (2 $1 / 2$ to $41 / 2$ years). Distal humeral epiphysis closed (A); olecranon ossification center well expanded and epiphyseal plate patent (B); proximal radial epiphyseal plate patent (C).

Fig. 3 Forepaw. Epiphyses of metacarpals and phalanges closing or recently closed (A). Epiphyses of radius and ulna patent (C). Carpal accessory bone (B) and sesamoid under head of first metacarpal indicate 3 years or more.

Fig. 4 Knee. Patella (A) well formed. Proximal tibial tuberosity present (B); (over $23 / 4$ years). Accessory under femur (C) well formed (three years or over) Head of fibula well formed (D).

Fig. 5 Hindpaw. Accessory bones present at A and C. Metatarsal and phalangeal. epiphyseal lines patent (B). $(2.3 / 4$ to $31 / 2$ years $)$. 


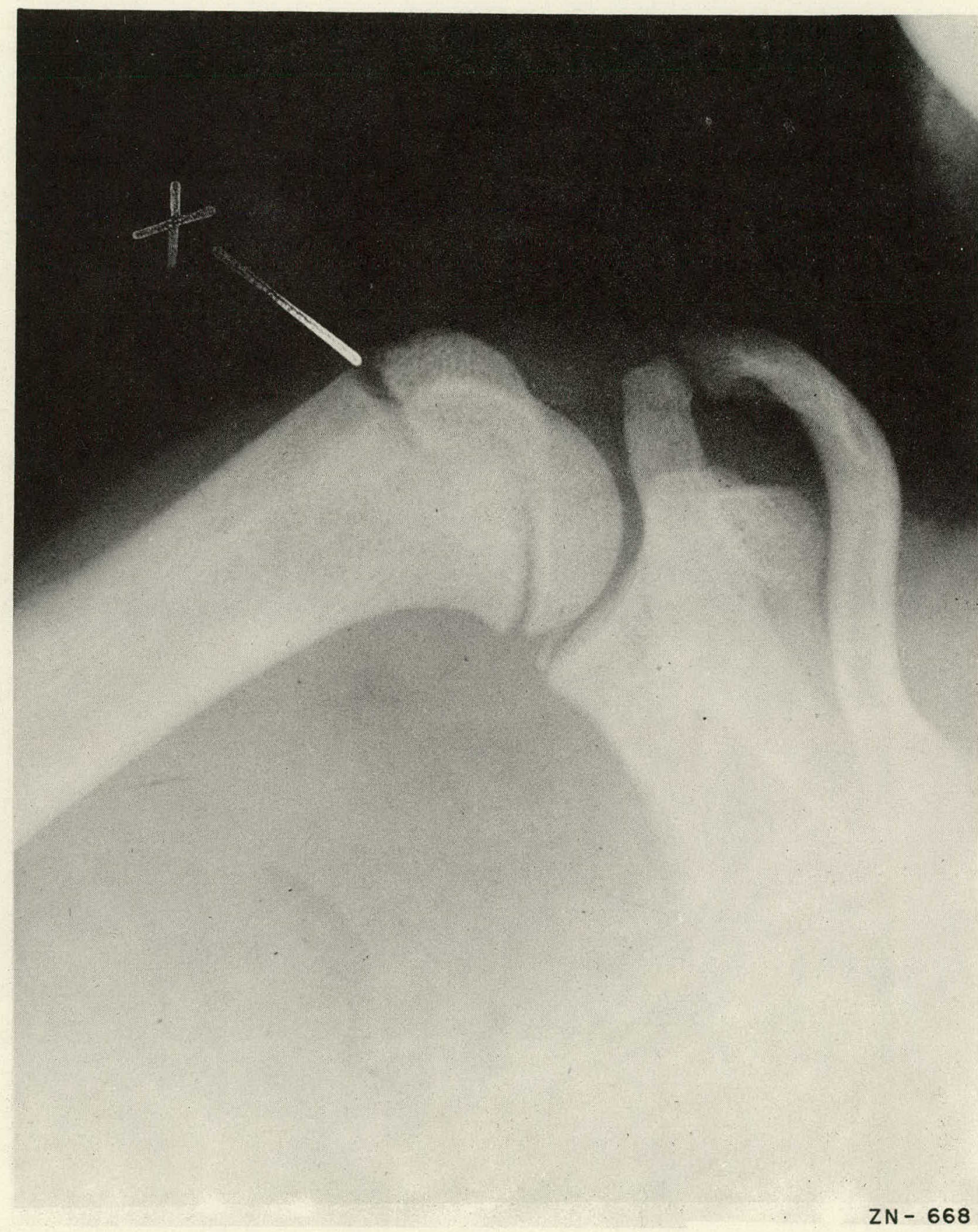

Fig. 1 


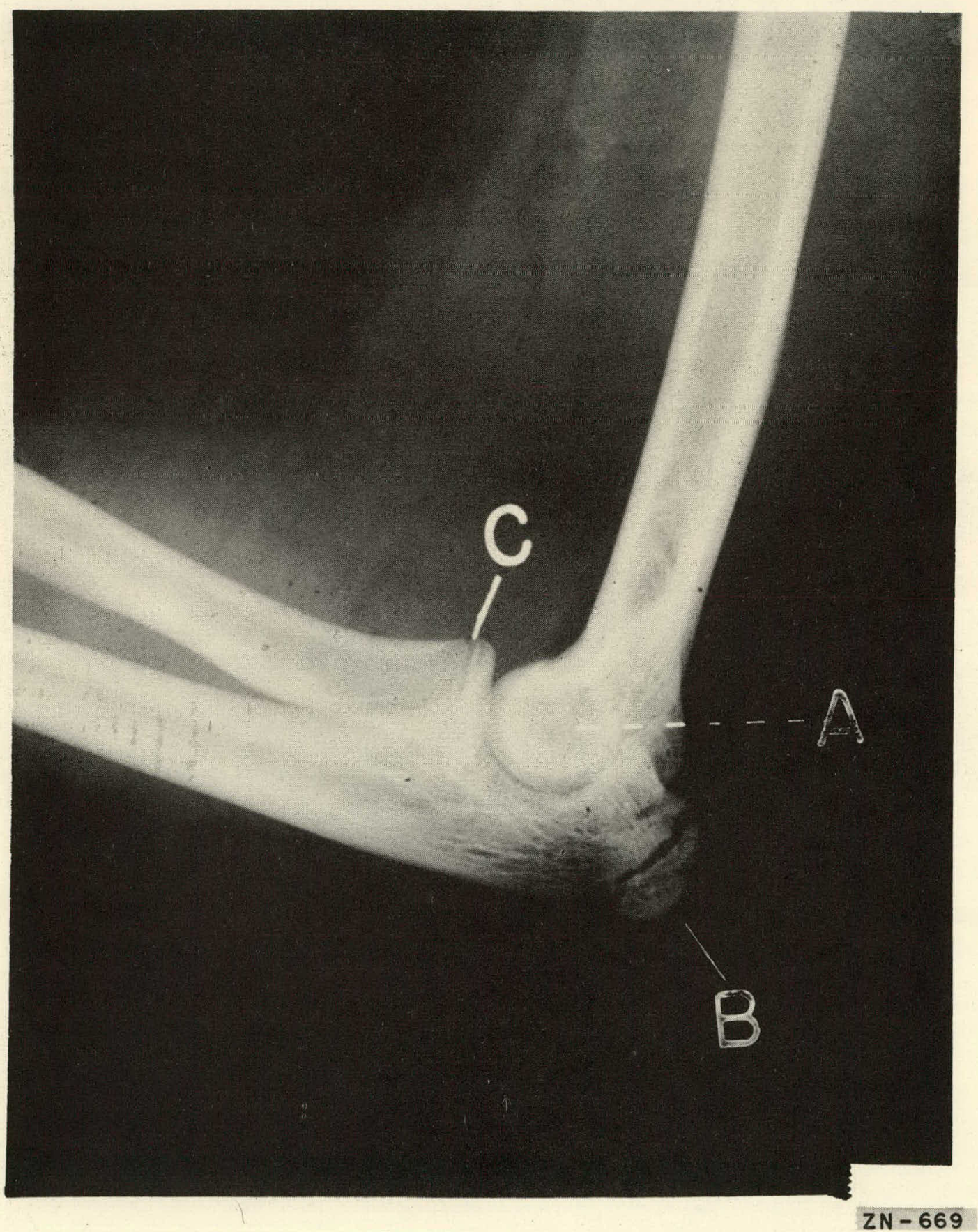

Fig. ? 


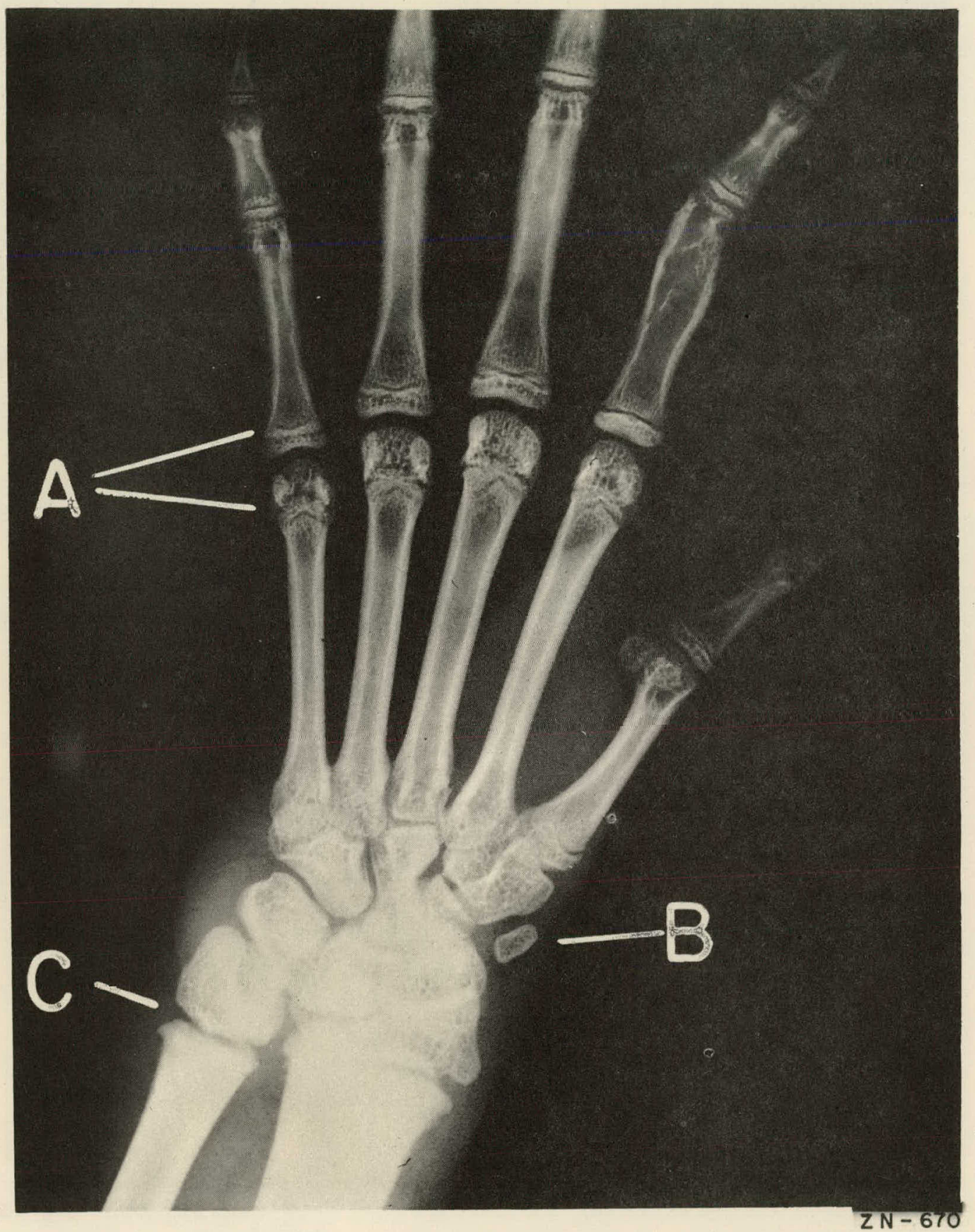

Fig. 3 


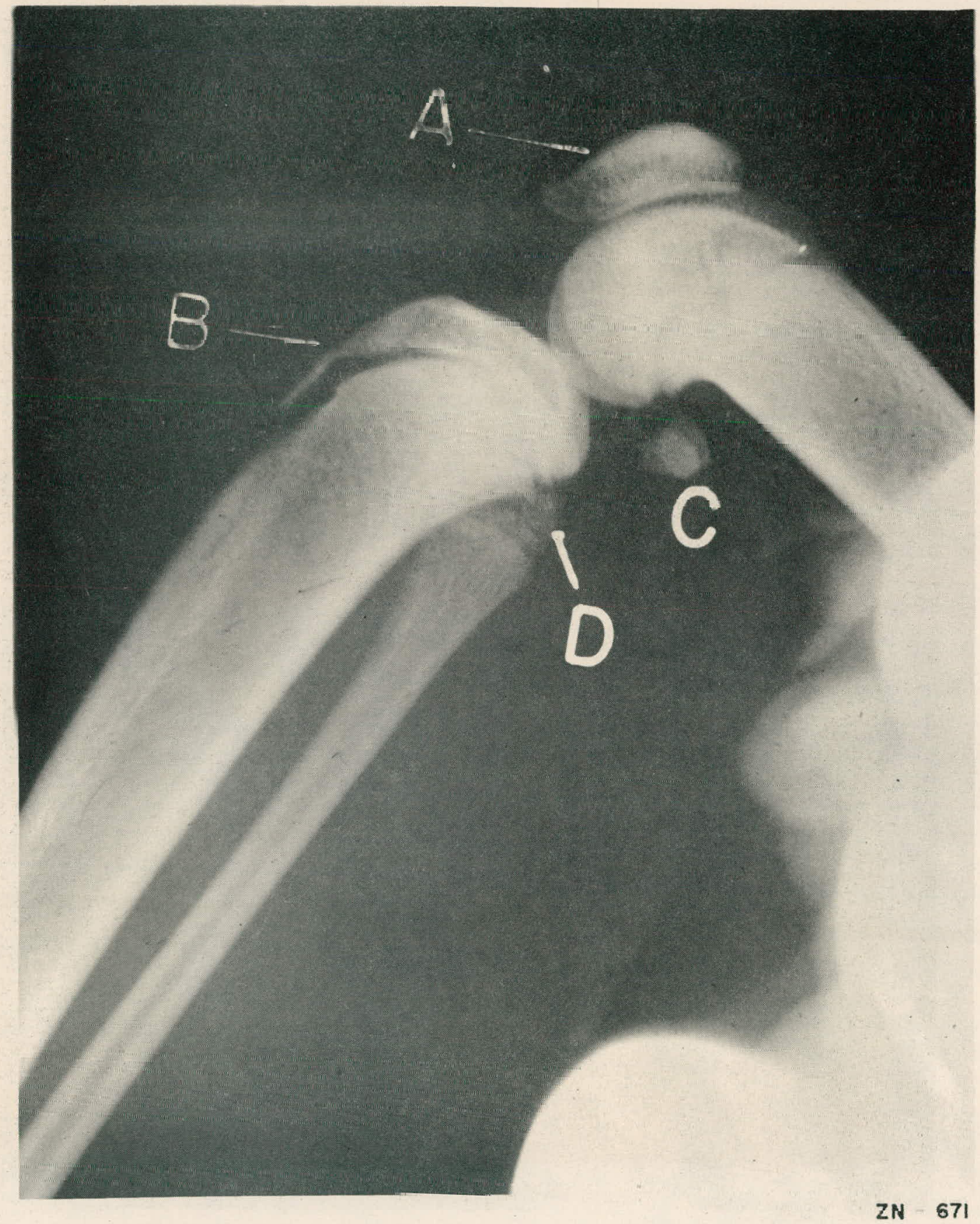

Fig. 4 


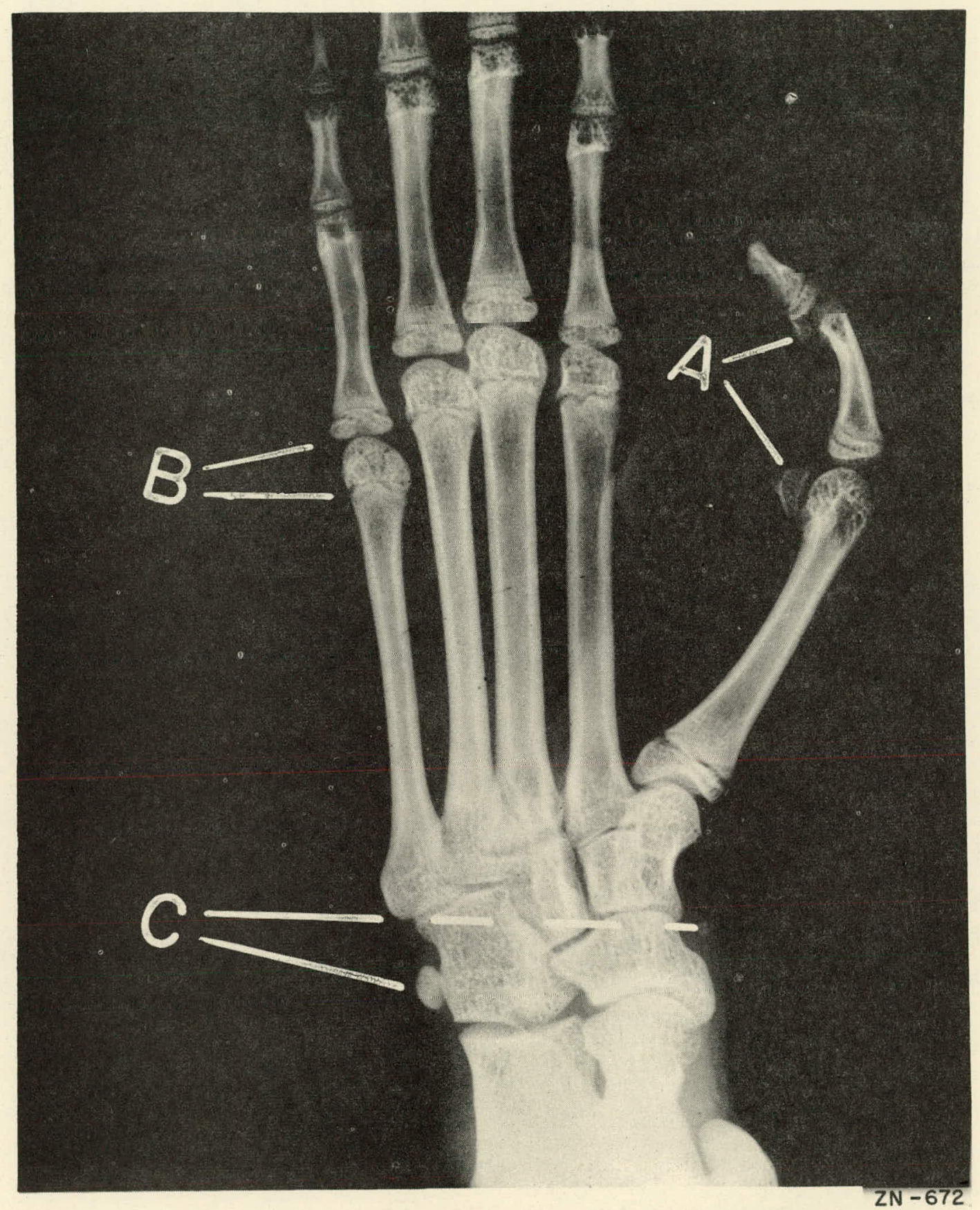

Fig. 5 


\section{RADIATION CHEMISTRY}

Warren M. Garrison

\section{Acetic Acid Studies}

Boyd M. Weeks, H. Ralph Haymond, and Winifred Bennett

In previous studies of the products formed in solutions of acetic acid by reactions resulting from irradiation with 35-Mev helium ions it was found, in the concentration range $0.0625 \mathrm{M}$ to $1 \mathrm{M}$, that the radiation yields $(\mathrm{G})$ of succinic acid, hydrogen, and hydrogen peroxide increase with acetic acid concen-" tration and approach a limiting value at the higher concentrations. The methane yield increases linearly over the entire range; G for carbon dioxide also increases with concentration but does not show a simple linear dependency. These data are summarized in Fig. $1 \mathrm{~A}$.

As previously discussed, the radiation yield of succinic acid, hydrogen, and hydrogen peroxide may be expected to increase in this manner if we assume that two primary radiation processes occur when dilute aqueous solutions are irradiated:

$$
\begin{aligned}
& \mathrm{H}_{2} \mathrm{O} \rightarrow \mathrm{H}+\mathrm{OH} \\
& \mathrm{H}_{2} \mathrm{O} \rightarrow{ }_{2} \mathrm{H}_{2}+{ }_{2} \mathrm{H}_{2} \mathrm{O}_{2}
\end{aligned}
$$

In the absence of added solute or at low solute concentrations the radicals produced in (1) react with $\mathrm{H}_{2} \mathrm{O}_{2}$ and $\mathrm{H}_{2}$ from (2), giving rise to the radiation-induced back reaction

$$
\begin{aligned}
& \mathrm{H}+\mathrm{H}_{2} \mathrm{O}_{2} \rightarrow \mathrm{H}_{2} \mathrm{O}+\mathrm{OH} \\
& \mathrm{OH}+\mathrm{H}_{2} \rightarrow \mathrm{H}_{2} \mathrm{O}+\mathrm{H}
\end{aligned}
$$

In the presence of acetic acid we have the possible competing reactions

$$
\begin{aligned}
& \mathrm{OH}+\mathrm{CH}_{3} \mathrm{COOH} \rightarrow \mathrm{CH}_{2} \mathrm{COOH}+\mathrm{H}_{2} \mathrm{O} \\
& \mathrm{H}+\mathrm{CH}_{3} \mathrm{COOH} \rightarrow \mathrm{CH}_{2} \mathrm{COOH}+\mathrm{H}_{2}
\end{aligned}
$$

which results in the formation of succinic acid via

$$
2 \mathrm{CH}_{2} \mathrm{COOH} \rightarrow \mathrm{COOH} \mathrm{C} \mathrm{CH}_{2} \mathrm{COOH}
$$

Radicals reacting with acetic acid are not available for reactions (3) and (4). The G values for succinic acid, hydrogen, and hydrogen peroxide may therefore be expected to increase with acetic acid concentration. The relative importance of (5) and (6) in the production of the $\mathrm{CH}_{2} \mathrm{COOH}$ radical has been determined from radiation-yield studies of $\mathrm{HD}$ formations in irradiated $\mathrm{CD}_{3} \mathrm{COOH}$ solutions. Upon irradiation of a $0.25 \mathrm{M} \mathrm{CD} 3 \mathrm{COOH}$ solution under conditions identical with those used in obtaining the data of Fig. 1, it was found, by mass spectrometric analysis, that HD accounted for less than 7.5 percent of the total hydrogen. Reaction (5) therefore presumably represents the major source of the $\mathrm{CH}_{2} \mathrm{COOH}$ radical. 
To determine the effect of ionization density on radiation yields in acetic acid solution, a series of irradiations was made with 18 -Mev deuterons. The results are shown in Fig. 1B. The dose rate and total dose were identical with those used in the helium-ion studies represented in Fig. 1A. Since the range of a deuteron of energy $E$ is twice that of a helium ion of energy $2 E$, the average ionization densities for the two particles are in the ratio $1 / 4$. The higher $G$ values observed in Fig. $1 B$ are in accord with the mechanism previously discussed. A comparison of the data in Figs. 1A and IB, however, brings out several relationships that require further consideration. On the basis of Hart's work on the formic acid-oxygen system it would appear that the total number of water molecules decomposed via (1) and (2) below may be considered a constant regardless of the type of radiation employed, i.e.

$$
\begin{aligned}
& \mathrm{H}_{2} \mathrm{O} \rightarrow \mathrm{H}+\mathrm{OH} \\
& \mathrm{H}_{2} \mathrm{O} \rightarrow 1 / 2 \mathrm{H}_{2}+1 / 2 \mathrm{H}_{2} \mathrm{O}_{2}
\end{aligned}
$$

The ionization density determines the fraction of decomposition via (1) or (2). The $G$ for the decomposition is estimated to be approximately 3.6 . In the acetic acid system, therefore, since we assume that $H$ does not react with acetic acid and that hydrogen is produced either via $\left(l^{\prime}\right)$ above or by the equivalent of

$$
2 \mathrm{H} \rightarrow \mathrm{H}_{2}
$$

the $G$ for hydrogen should reach a limiting value of approximately 1.8 . This is apparently the situation in the deuteron case (Fig. 1B). At higher ionization densities however, i.e. with helium ions (Fig. 1B), the hydrogen yield reaches a limiting value close to 1.0 . One obvious explanation for lower hydrogen values obtained with helium-ion irradiation is that the mechanical agitation given the target cells is not sufficient to remove the water decomposition products from the irradiation zone so that $O H$ radicals are still removed by radical recombination or by reaction (4) even at the highest acetic acid concentrations. If this were the situation, rapid mechanical stirring of air free solutions should result in a pronounced increase in the yield of succinic acid. In Table I are given $G$ values for succinic acid and hydrogen peroxide obtained under two widely differing conditions of stirring.

Part A shows the results obtained with the standard evacuated-target procedure previously described. Part B shows the corresponding radiation yields obtained when a mechanical stirrer is rotated at approximately $1700 \mathrm{rpm}$ directly behind the irradiation zone. Helium was bubbled through these solutions to prevent oxygen contamination and to remove hydrogen. It is seen that there is $a$ definite although relatively small differençe in the observed yields under these two widely differing hydrodynamic conditions. This would indicate that the lower $G$ values obtained with helium ions do not result from a competition between acetic acid and water products for $O H$. There is the possibility, however, that such a competition exists within the particle track volume.

The carbon dioxide and methane yields for both helium ion and deuteron irradiation do not show the same type of concentration dependency. Figure 2 shows produce $G$ values as a function of acetic acid concentration up to $16 \mathrm{M}$ acetic acid. These data were obtained by helium-ion irradiation under standard target conditions. The carbon dioxide and methane yields show a linear dependency on concentrations up to $16 \mathrm{M}$ acetic acid. The yields of succinic acid, 
$-50-$

UC $21,-2345$ 
Table I

Effect of Stirring on the Radiation Yield of Succinic Acid and Hydrogen Peroxide in Oxygen-Free Acetic Acid Solutions.

$\begin{array}{ccccc}\begin{array}{c}\text { Aectic Acid } \\ \text { conc } \frac{\mathrm{M}}{0.0625}\end{array} & \mathrm{G}_{\mathrm{s}} & \mathrm{G}_{\mathrm{H}_{2} \mathrm{O}_{2}} & \mathrm{G}_{\mathrm{s}} & \mathrm{G}_{\mathrm{H}_{2} \mathrm{O}_{2}} \\ 0.125 & 0.17 & 0.29 & 0.14 & 0.23 \\ 0.25 & 0.26 & 0.33 & 0.23 & 0.26 \\ 0.50 & 0.28 & 0.35 & 0.31 & 0.28 \\ 1.00 & 0.30 & 0.37 & 0.35 & 0.31 \\ & 0.32 & 0.40 & 0.36 & 0.34\end{array}$

A. Standard Conditions

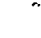

0.32

0.40

0.36 


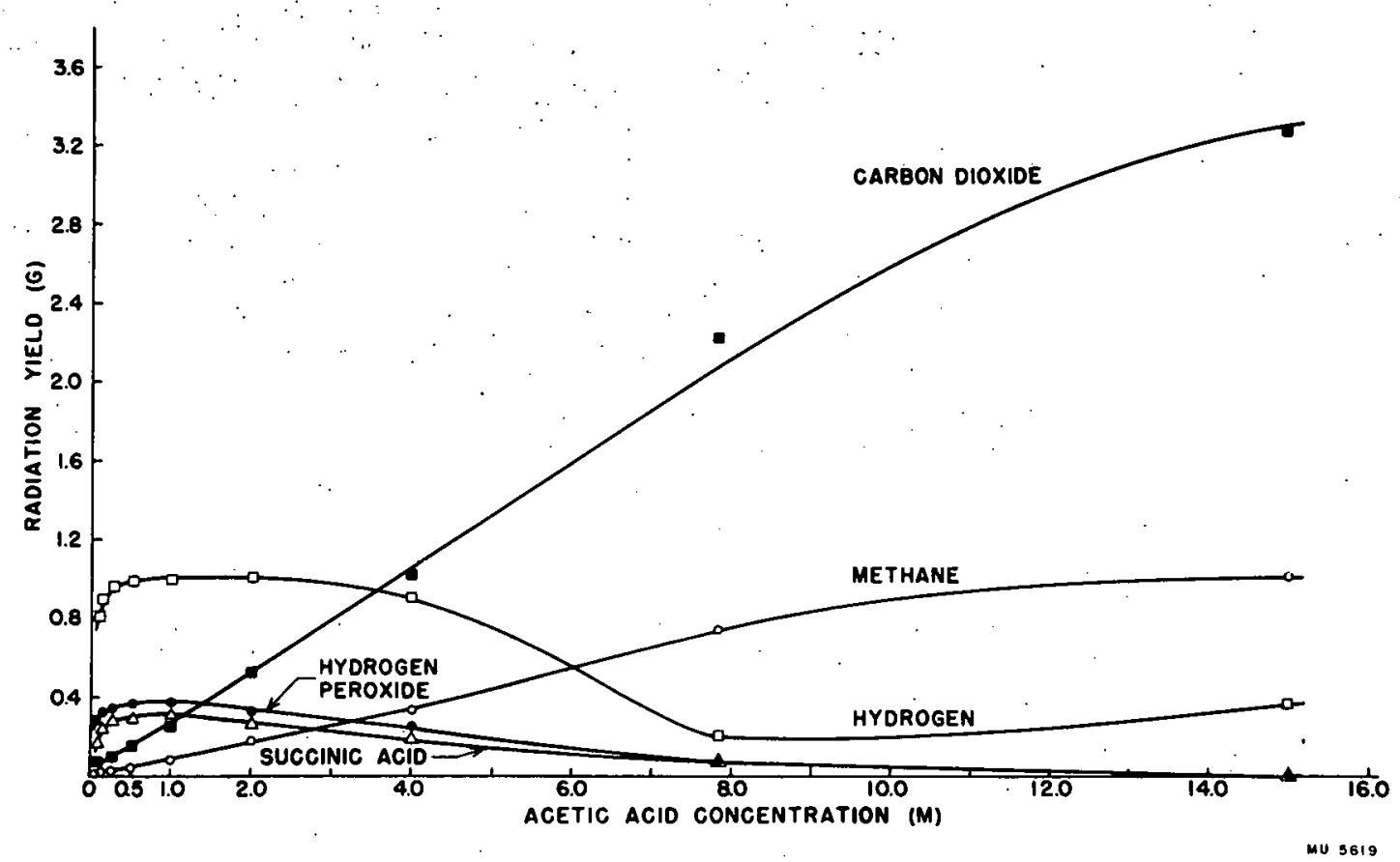

Fig. 2 
hydrogen, and hydrogen peroxide reach a limiting volume and then decrease as the fraction of energy absorbed in water decreases. These results suggest that carbon dioxide and methane are produced by direct action of the radiation on acetic acid molecules. The fact that these two products are not in stoichiometric amounts indicates further that more than one direct process is involved. These data ${ }^{\circ}$ will be discussed in more detail in subsequent reports.

The effect of oxygen on the helium-ion irradiation of acetic acid solutions has been investigated. Previous reports have shown that the presence of oxygen results in a decrease in succinic acid and an increase in hydrogen peroxide. The results from a series of helium-ion irradiations in which the solutions were mechanically stirred and at the same time aerated with a stream of oxygen are shown in Table II. The effect of stirring is to increase the oxygen concentration in the irradiation zone. Oxygen competes for radicals via

$$
\begin{aligned}
& \mathrm{H}+\mathrm{O}_{2} \rightarrow \mathrm{HO}_{2} \rightleftarrows \mathrm{H} \mathrm{O}_{2} \\
& \mathrm{CH}_{2} \mathrm{COOH}+\mathrm{O}_{2} \rightarrow \mathrm{O}_{2} \mathrm{CH}_{2} \mathrm{COOH}
\end{aligned}
$$

Peroxide may then be produced by

$$
2 \mathrm{HO}_{2} \rightarrow \mathrm{H}_{2} \mathrm{O}_{2}+\mathrm{O}_{2}
$$

The succinic acid yield is decreased as a result of the reaction between oxygen and the $\mathrm{CH}_{2} \mathrm{COOH}$ radicals. The fate of the $\mathrm{O}_{2} \mathrm{CH}_{2} \mathrm{COOH}$ radical has not been established, although data obtained from sealed targets (Table III) show that the carbon dioxide yield increases as the succinic acid yield decreases. The $\mathrm{O}_{2} \mathrm{CH}_{2} \mathrm{COOH}$ radical may form glycolic or glyoxalic acid.

$$
\begin{aligned}
& \mathrm{O}_{2} \mathrm{CH}_{2} \mathrm{COOH} \mathrm{H}_{2} \mathrm{O} \rightarrow \mathrm{CH}_{2} \mathrm{OHCOOH}+\mathrm{HO}_{2} \\
& \mathrm{O}_{2} \mathrm{CH}_{2} \mathrm{COOH} \rightarrow \mathrm{CHOCOOH}+\mathrm{OH}
\end{aligned}
$$

Neither of these acids is recovered in the nonvolatile acid fraction that contains the succinic acid. Other analytical techniques are being developed for their determination. 


\section{Table II}

Effect of Stirring on Radiation Yields of Succinic Acid and Hydrogen Peroxide in Aerated Solutions of $0.25 \mathrm{M}$ Acetic Acid.

\begin{tabular}{|c|c|c|}
\hline$\underset{\text { Spm }}{\text { Stirring Speed }}$ & $\mathrm{G}_{\mathbf{s}}$ & $\mathrm{G}_{\mathrm{H}_{2}} \mathrm{O}_{2}$ \\
\hline 300 & 0.078 & 0.73 \\
\hline 600 & 0.060 & 0.80 \\
\hline 1200 & 0.031 & 0.94 \\
\hline $1200^{\circ}$ & 0.00 & 1.01 \\
\hline
\end{tabular}

Table III

Effect of Oxygen on Radiation Yields in $0.25 \mathrm{M}$ Acetic Acid Solutions.

Product

Hydrogen Peroxide

Hydrogen

Carbon Dioxide

Succinic Acid
Evacuated

0.35

0.96

0.10

0.28
Oxygen Present

0.70

0.75

0.49

0.14 
Determination of Aldehydes and Ketones in Irradiated Solutions of Organic Acids

H. Ralph Haymond

Determination of total carbonyl compounds in irradiated acetic acid solutions has been investigated by several methods based on measurement of the quantity of 2,4-dinitrophenylhydrazones formed when the ketones and aldehydes react with 2,4-dinitrophenylhydrazine. In one method; similar to that of Greenberg and Lester, 1 the hydrazones were formed in acid aqueous solution and extracted into carbon tetrachloride. The concentration of hydrozones in the carbon tetrachloride phase was measured on a Cenco photolometer with blue filter by comparison with solutions containing known amounts of acetone. Results obtained by this method indicate that the amount of carbonyl-containing compounds formed during irradiation is approximately linear with the concentration of acetic acid irradiated. This method has the disadvantage of an extraction process for which the extraction ceofficients of all the possible product carbonyl compounds are not known.

Another method, based on that of Lappin and Clark, 2 does not involve an extraction and is suitable to the concentrations in which we are interested. In this method the concentration of the hydrozones is measured in basic methanol solution at $480 \mathrm{m \mu}$ on a Beckmann model DU spectrophotometer. Neither of these methods distinguishes between the 2,4-dinitrophenylhydrazones of the ketones and aldehydes that may be present as products of irradiation. For the purpose of identification, a method of chromatography of the hydrozones on dry silicic acid, with ether-petroleum ether solutions as eluting solvents, has been investigated. This method has given results which indicate that acetone is a principal carbonyl-containing product of irradiation of acetic acid solutions. It is similar to a method used by. Marvel, Bluestein, Schilling, and Sheth. 3

1 L. A. Greenberg and D. Lester, J. Biol. Chem. 154, 177 (1944).

2 Gerald R. Lappin and Leland C. Clark, Anal, Chem. 23, 541 (1951).

3 C. S. Marvel, Claire Bluestein, W. M. Schilling, andP. G. Sheth, J. of Org. Chemistry, 16, 854 (1951). 


\section{Glycine Studies}

Boyd Weeks

A detailed outline of a study of the radiation chemistry of aqueous glycine solutions was presented in the quarterly report for October-December 1952 (UCRL-2111) and elaborated upon in the succeeding quarterly report. Dur ing the period of the present report, progress was made in the problem of target preparation and volatile-product analysis.

Preparation of Target Material

The chromatographic procedure already described for the preparation of free glycine has been found unsuitable. It was found impossible to entirely prevent erosion of the resin by the solvents used. Even"though this erosion is minute and is undetectable in small samples of effluent liquid from a continuously running column, the large volumes of solvent and the relatively long periods of time during which the resin is immersed in solvent, which ultimately must be separated from the glycine, provide ample opportunity for resin debris and solvent impurities to accumulate to an appreciable extent in the final glycine preparation. Deterioration of the resin (Dowex 50) was found to take place in distilled water and to a greater extent in the acid and alkali solutions used to elute the glycine. The ion-exchange column remains unexcelled, however, an an analytical tool for the isolation of the various cationic products in the presence of the relatively large amounts of parent glycine. For the present, standard methods of recrystallization from doubly distilled water with about 50 percent recovery are being employed for the preparation of glycine for bombardment.

A one-gram sample of crude glycine (Nutritional Biochemicals Corp.) was analyzed by ion-exchange chromatography, and traces of at least two ninhydrin-positive impurities amounting to less than 1 percent of the total glycine were detected. Less laborious methods employing filter-paper chromatography are now being investigated to set limits on the various possible contaminants in our glycine preparations.

Bombardment

Two evacuated glass targets containing $100 \mathrm{ml}$ each of $0.25 \mathrm{M}$ glycine prepared by recrystallization from water were given standard doses of $3.9 \times 10^{22}$ ev of $34.5-\mathrm{Mev} \mathrm{He}$ ion irradiation.

Isolation and Determination of Products

Volatile and gaseous products only were investigated in these two bombardments. $\mathrm{H}_{2}, \mathrm{CO}_{2}$ and $\mathrm{H}_{2} \mathrm{O}_{2}$ were determined in the usual manner. Tests for hydrazine, hydroxylamine, methylamine and ammonia are being carried out as follows:

1. Hydrazine forms an insoluble aldazine with salicylaldehyde, and a test involving this reaction was negative for samples of the bombarded glycine solution. As little as $0.00005 \mathrm{M}$ hydrazine in $0.25 \mathrm{M}$ glycine will give a positive test.

2. Hydroxylamine reacts with salicylaldehyde and cupric acetate to form an insoluble yellow oxime. A test based on this reaction was negative for the bombarded glycine solutions where $0.001 \mathrm{M}$ hydroxylamine in $0.25 \mathrm{M}$ glycine is easily detected. 
3. Samples of the target solutions were made alkaline with $\mathrm{NaOH}$ and distilled in vacuo. The distillate was then titrated using a Beckman pH meter, and the resulting titration curves showed evidence of a mixture of at least two weak bases. A simulated sample using a 3:1 mixture of methylamine and ammonia gave an almost identical titration curve.

Mass spectrometric analyses of concentrated sample's of the volatile basic fractions of the target solutions show mass spectra resembling that of methylamine: Work is now in progress to increase the sensitivity of the mass spectrometric analysis of small amounts of volatile base in water solution, and a similar approach will be made for the examination of the volatile acid products. The. details of a method employing ion-exchange chromatography are being worked out for the isolation of the se volatile basic products, which are neither ninhydrinpositive nor radioactive when the parent glycine is tagged with $C^{14}$. 


\section{HEALTH CHEMISTRY}

N. B. Garden

\section{PROGRESS REPORT}

\section{Equipment Development Group}

Several samples of irradiated materials from the Idaho Falls reactor have been processed in standard Health Chemistry equipment, which equipment usually includes the two-inch lead shields in conjunction with related remotecontrol equipment. The materials irradiated included specially prepared soils and rare earths.

Three slugs for irradiation in the Idaho Falls reactor, containing large amounts of alpha-active material, were prepared in conjunction with Chemistry personnel in a series of gloved boxes set up in Bldg. 5A Annex, where chemical processing of the material took place, and in boxes set up in the decontamination chamber in Bldg. 5A, where encapsulation was accomplished. Because of the necessity of performing chemistry steps which were not planned on in the purification of the material, the equipment was heavily taxed, especially the filter system; the manifold, to which some eight gloved boxes were connected, was so contaminated that it has been necessary to remove the manifold system for decontamination; boxes on the system in which operations continued to be conducted were rigged up to temporary ventilating systems. Despite the large quantities of materials involved, the activity remained enclosed and contamination of the area did not occur. In the final tailoring of the slugs, sandblasting for removal of contamination on the surface of the slug was successfully effected within a gloved box.

Several more shipments of Hanford waste solution from which americium is extracted have been received and processed in the equipment set up in Bldg. 5A.

The processing of large quantities of special soils., described previously, is continuing; the equipment and processes used are now fairly well established, with minor improvements or modifications being made from time to time.

The housing for a low-geometry counter to be assembled in the Cave Room of Bldg. 5 has been completed. This counter is being created so as to minimize transportation of high-activity counting discs from this laboratory to the counting rooms. With the higher levels of activity now handled in the laboratories, these discs sometimes go as high as $10^{8}$ counts per minute. The housing includes a two-inch lead shield sampling system.

This group continues to spend the major part of its time in designing and fabricating boxes and auxiliary equipment for processes at Livermore and in connection with Livermore. 
During this period $850 \mathrm{~kg}$ of normal uranium turnings resulting from various machining jobs during the past three years were dispatched in fourteen barrels to a recovery center at Hanford. They were successfully packaged in drums equipped with lids having rubber breathers similar to those used in shipments between Los Alamos and Oak Ridge; thus the prevention of hydrogen pressure was effected. The turnings were covered with oil.

During this period fourteen tanks of 800 gallons each were received from Livermore containing low-level active waste. This material has been treated by purifying it through precipitation with iron hydroxide, plus Dowex 50 and Dowex 1 if necessary, and allowing the precipitate to settle; the supernate is then decanted off, and when negative as far as being a sewage contaminant is concerned, the liquid is poured into the sewage system.

The paved area at the rear of Bldg. 5, which is used for storing and packaging radioactive waste, has been coated with various experimental materials in order to find a surfacing material that will prevent the inevitable low-level activity, which accumulates from this type of work, from becoming imbedded in the pores of the concrete. About three-quarters of the area was coated with paraffin which had been dissolved in carbon tetrachloride; an alternate method of applying the paraffin was to heat the concrete with an oxyacetylene torch and then to pour melted paraffin on it. On the remaining area various commercial coatings were tried, but the paraffin treatment seems to be the most successful.

The use of Sno-Gel for gelatinization of active waste is proving useful in providing an easy means of solidifying active liquid waste to be incorporated in the cement drums for disposal at sea:

\section{Airborne Activity Control Group}

Corisultations on minor design considerations involving Bldg. 70 at Berkeley and Bldg. 101 at Livermore took place during this period. Design studies involving Room 103, Bldg. 153 facilities consumed many hours of consultations leading to the design of successful equipment; one item,developed was an essentially closed-system, inert atmosphere, ventilation and air cleaning train, fabricated, installed and successfully operated to handle pyrophoric radioactive materials, that had to be accounted for during machining operations.

A saran bed scrubber (30-gallon model), in which the scrubbing liquid is circulated through a column composed of saran fibers and driven by an air lift, has been field tested and found satisfactory.

Berkeley Box Group

During this period the trend toward construction of job-specialized equipment continued. It is frequently possible to use many items of standard equipment in this work, as many of the designs for special enclosures are based on dimensions of Health Chemistry stock equipment items, such as inlet air filter assemblies, doors, glove ports, etc. Standardized techniques as developed by the Berkeley Health Chemistry group have simplified the approach to construction of such specialized enclosures and equipment used mainly at Livermore. 
In view of the recent increase in requests for equipment of the above specialized construction nature, stocks of standard gloved boxes are maintained with some difficulty; nevertheless, the group has been able to keep the general stocks in fairly good order.

Some forty gloved boxes were assembled and fitted on requests of experimenters during this period. 


\section{HEALTH PHYSICS}

Burton J. Moyer

\section{STATISTICAL SUMMARY OF MONITORING PROGRAM}

Survey Instruments Maintained

B $-\gamma$ Ionization Chamber

I. D. L. Portable Survey Instruments

Cutie Pies

Recording $\gamma$-Intensity Meters

Victoreen Proteximeter

East-Neutron Proportional Counters

Slow-Neutron Proportional Counters

Fast-Neutron Proportional Counter (Portable) .

Slow-Neutron Portable Unit

Balanced Chamber - Fast Neutron - Portable

Special Tissue Wall Survey Instrument

Personnel Meters in Use

Total Personnel Covered with Film Badges

Total Man Days Coverage with Pocket Chamber

Total Man Days Coverage with Pocket Dosimeters

3,012

Total Man Days Coverage with Pocket Chambers (S.N.)

2,700

Cases of Weekly Exposure above 0.3r

Weekly Film

\begin{tabular}{|c|c|c|c|c|c|c|}
\hline Expos. above & $184^{\prime \prime}$ Area & $60^{\prime \prime}$ Area & Lin. Acc. & Chem. & Other & Total \\
\hline 0.3 & 0 & 10 & 15 & 28 & 5 & 58 \\
\hline 0.5 & 0 & 3 & 4 & 16 & 1 & 24 \\
\hline 1. 0 & 0 & 1 & 0 & 5 & 1 & 7 \\
\hline 1.5 & 0 & 0 & 0 & 1 & 0 & 1 \\
\hline 2.0 & 0 & 0 & 0 & 0 & 0 & 0 \\
\hline 2.5 & 0 & 0 & 0 & 0 & 0 & 0 \\
\hline
\end{tabular}


